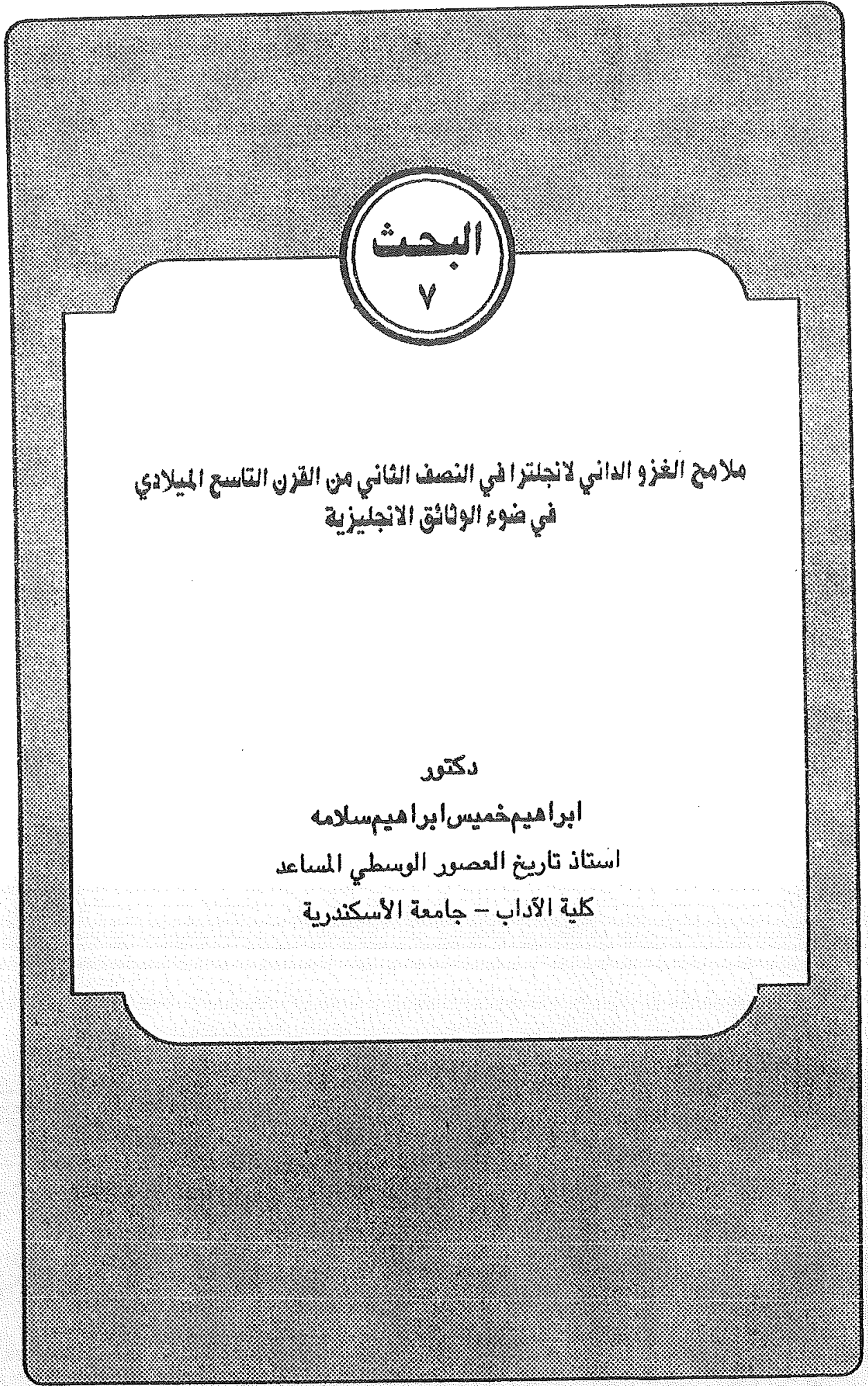


- YYY - 


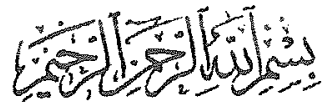

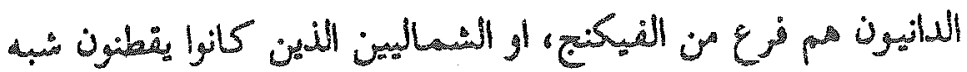

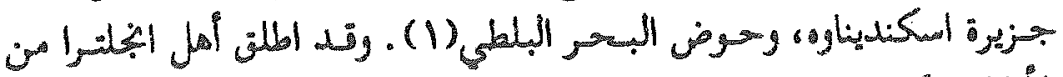

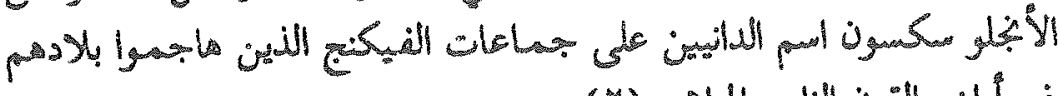

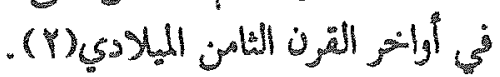

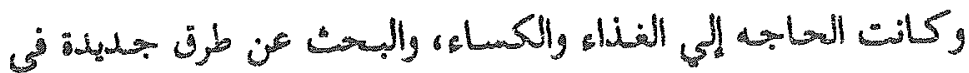

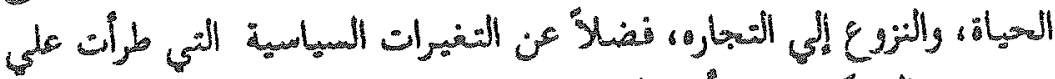

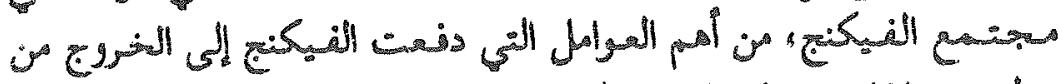

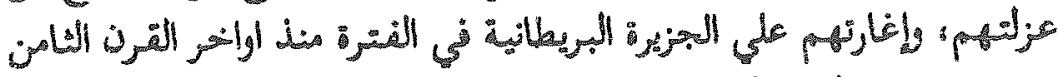

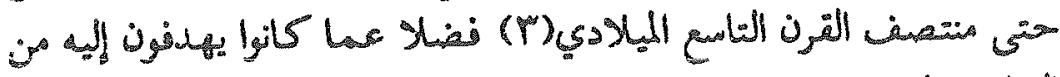

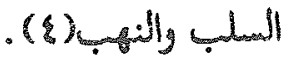

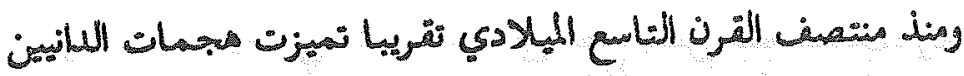

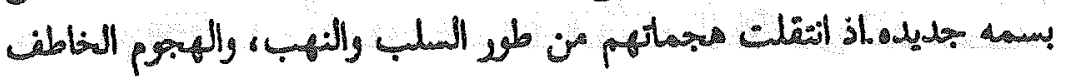

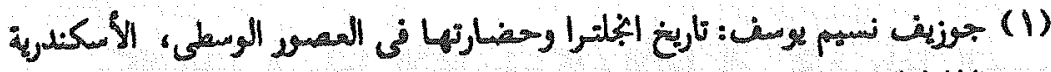
.181 o splat

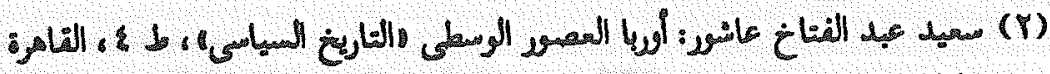

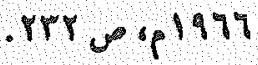

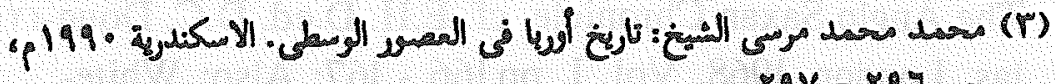
.Y१Y - Y१Y

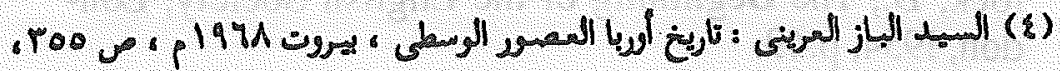
وإيضا :

Koenigsberger, H.G., Medieval Europe (400 - 1500), New York, 1987,p. 96; Morris, B., The Midudile Ages, New York, 1983, P. 58. 


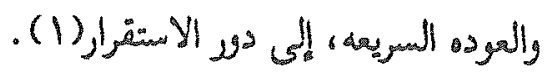

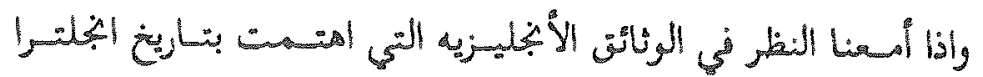

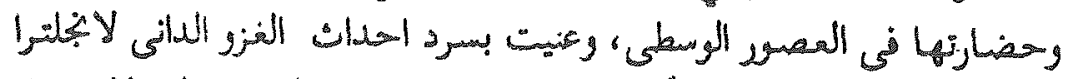

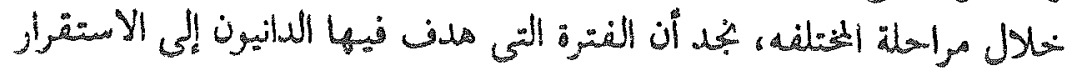

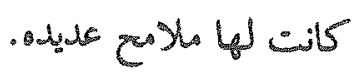

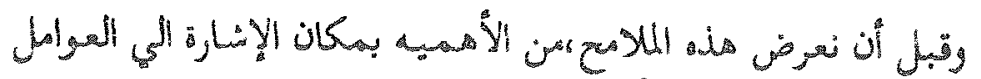

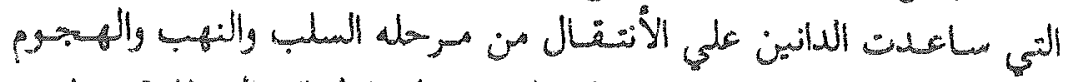

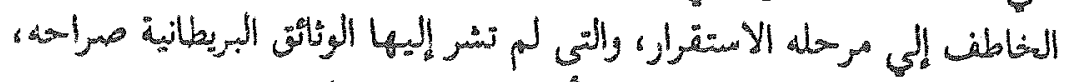

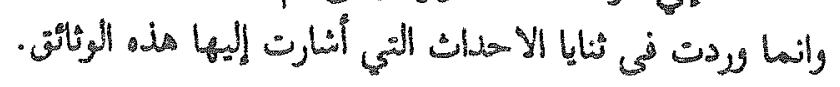

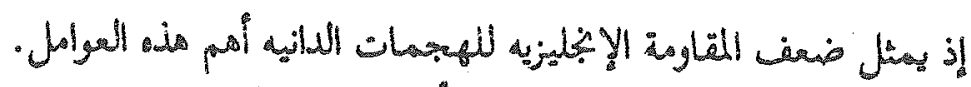

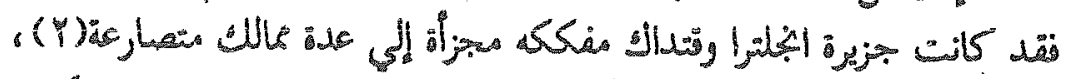

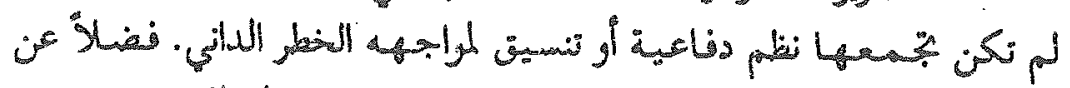

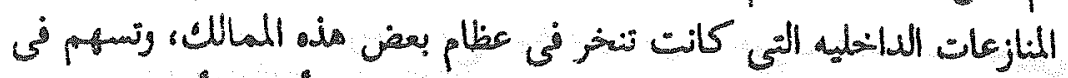

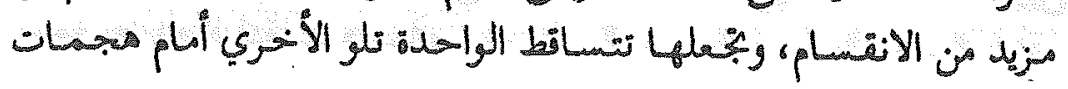
الدانتيين(r)

وكان لطول السواسل الاجمليزية،وكرة الأنهار التي ثري دانل الجزيره

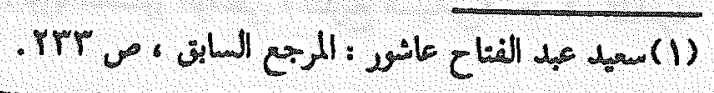

The Anglo Saxan Chronicle, cf. E.H. D.ed. D.C. Doug-(r) las, London, 1968, Vol. I, pp.166 - 167; Also; Whitelock, D., The Beginning of the English Society, London, 1954, p.49.

Roger de Hoveden, The Annals, 2 Vals, London, 1853,(r) Vol. I, pp.44 - 49, 160. 


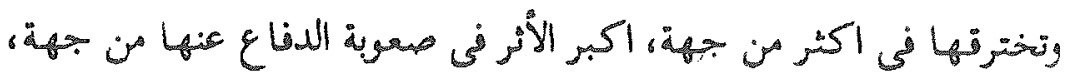

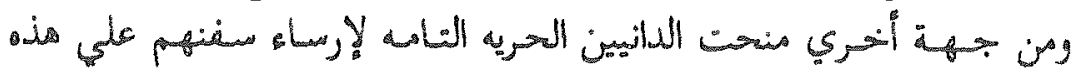

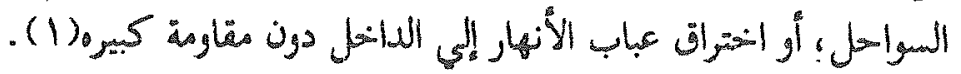

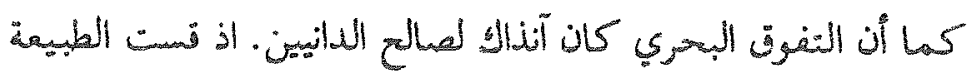

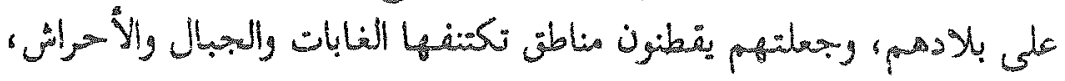

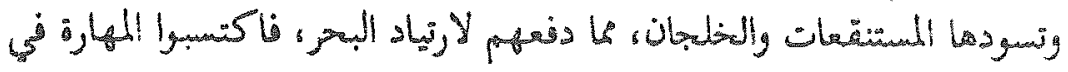

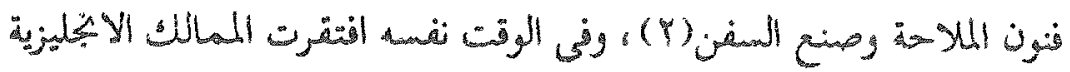

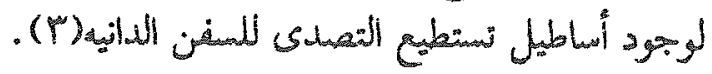

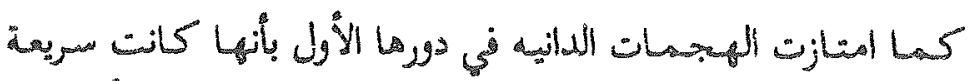

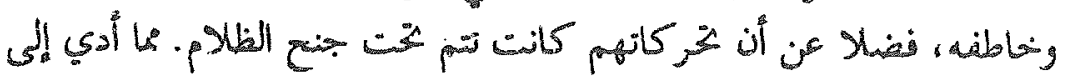

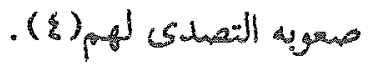

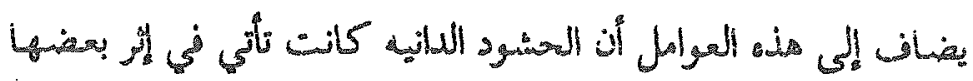

The Anglo Saxn Chronicle, Cf. E.H. D., P. 166.

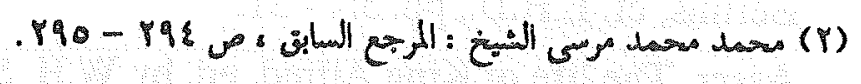

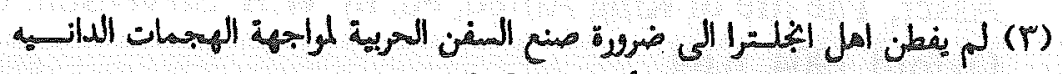

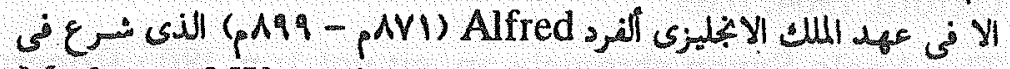

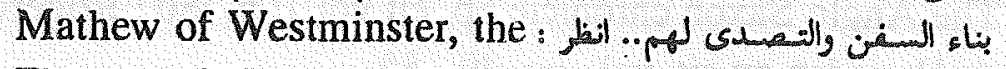
Flowers of History, 2 Vols, London, 1853, Vol. I, pp. .428 - 429 .

Roger de Hoveden, op. cit., Vol. I, pp. 49,55; The Anglo( $($ ) Saxon Chronicla, if .E.H.D., Vol. I, P.173 


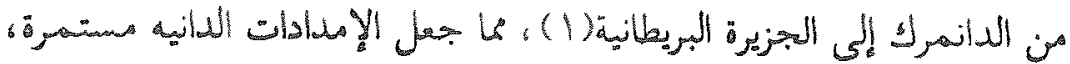

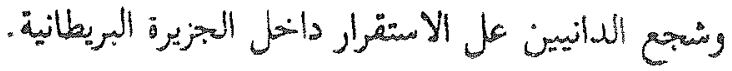

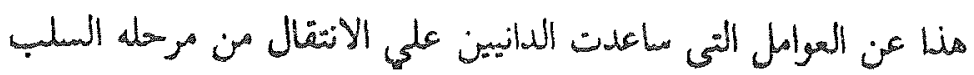

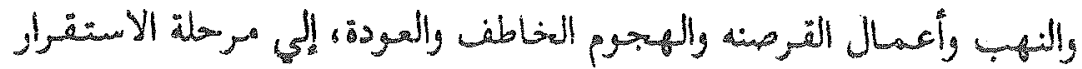

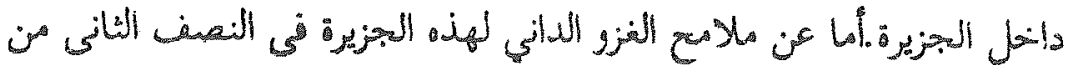

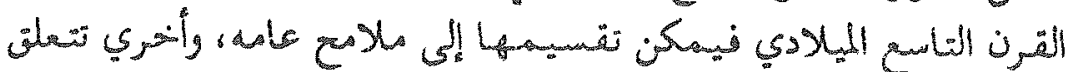

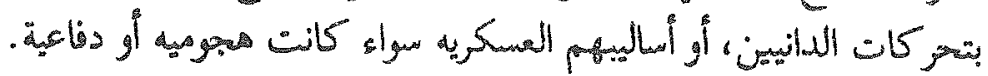

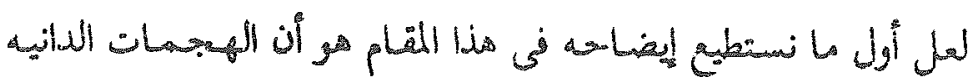

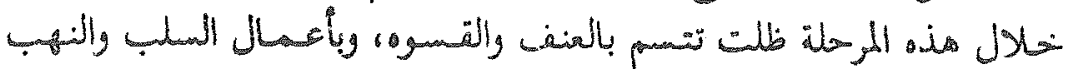

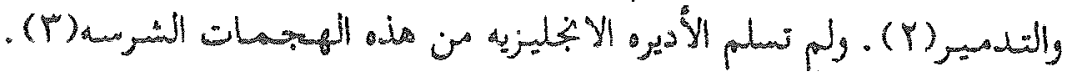

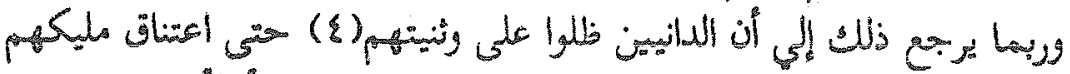

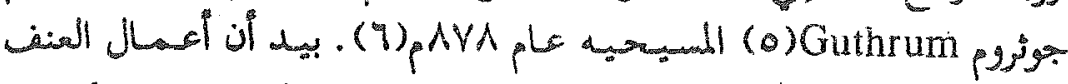

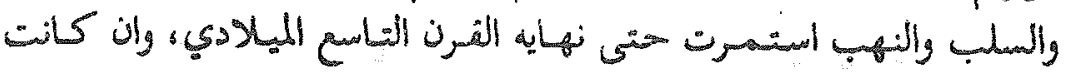

Roger de Hoveden, op, cit., vol. 1, p.43; Annals of St.. (1) Bertins, cf. E.H.D., pp. $314-315$

Asscr, The life of King Alfred, ed. by W.H. Stevenson, $(Y)$ Oxford, 1904, p.69.

The Anglo Saxon chronicle op. cit vol 1; p. 180 ; Roger(r) de Hoveden op cit, vol, pp. 49 - 50.

Trevalyan, G. M., History of England, London, 1924, p.(₹) 69.

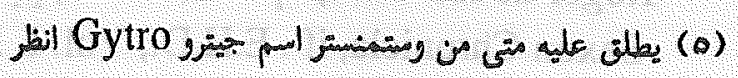

Matthew of Westminster op. cit, vol. I, p.429.

The Anglo Saxan Chronicle op.cit, vol. I, p.180. 
هحدوذ واخف وطأه من الهجمات التي تمت قبل مام AVA (1) .

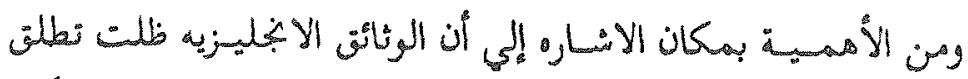

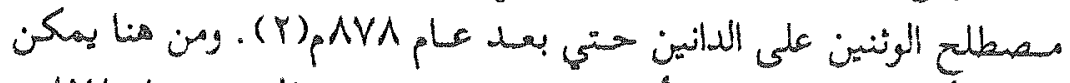

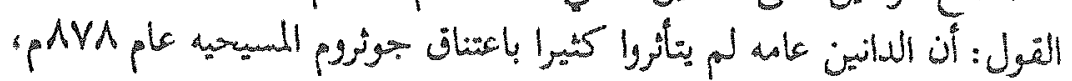

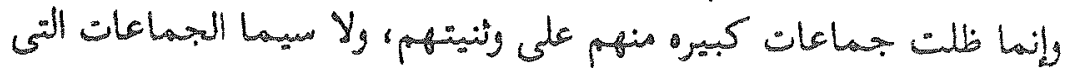

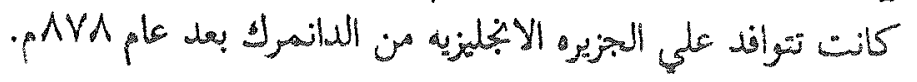

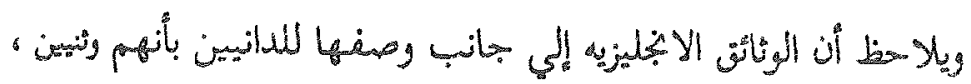

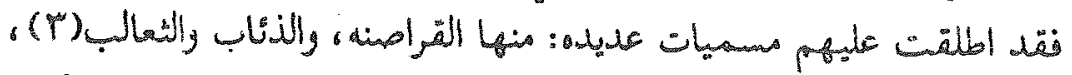

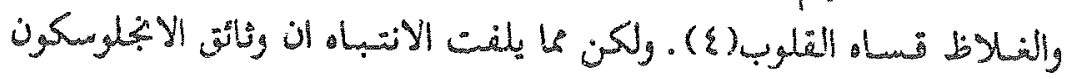

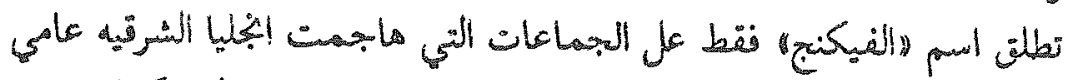

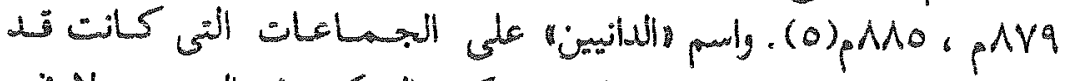

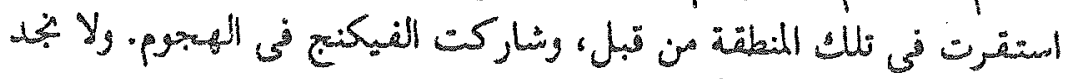

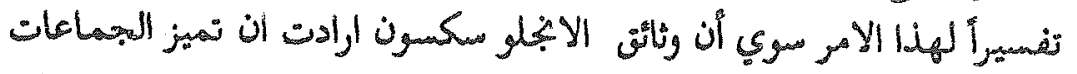

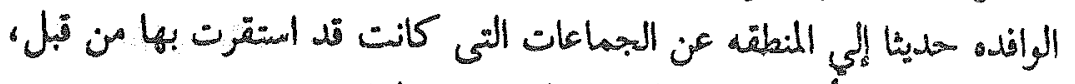

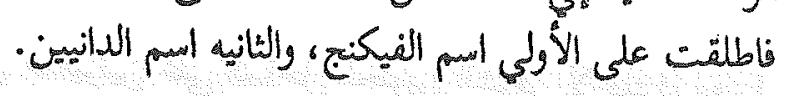

Roger deHoveden op. cit, vol. 1, p. 58.

Roger de Hoveden op cit., vol. I, pp. 50 - 58; Matthew (Y) of westminster, op. cit, vol I, pp. 433 - 437.

Roger de Hoveden op. cit., Vol. I, pp. 47, 49.

Letter of pope John VIII to Ethelred archbichop of Can-( $₹$ ) terbury, of . E. H. D., Vol. I, p. 811.

The Anglo Saxon Chronicle, op. cit, vol. I, pp. 180, (o) 182. 


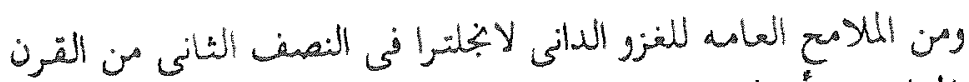

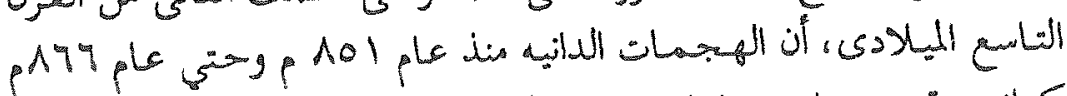

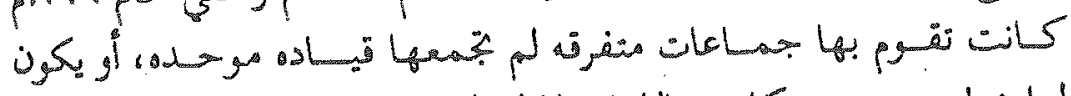

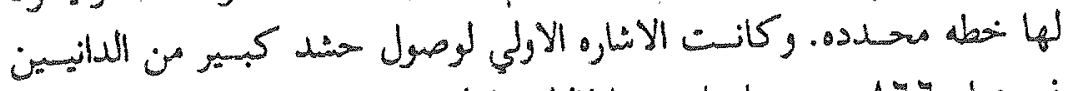

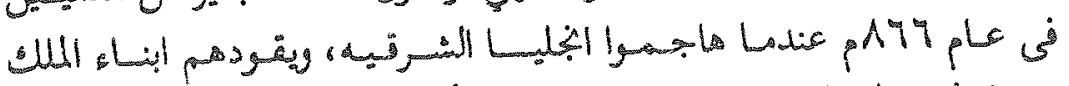

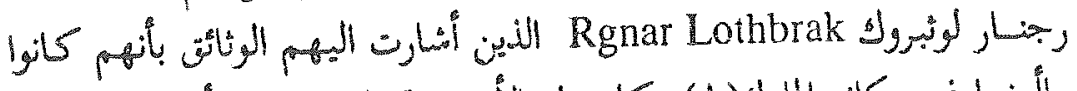

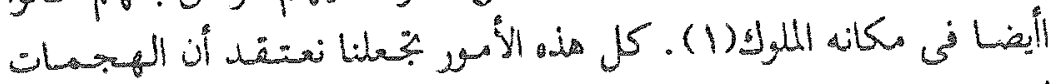

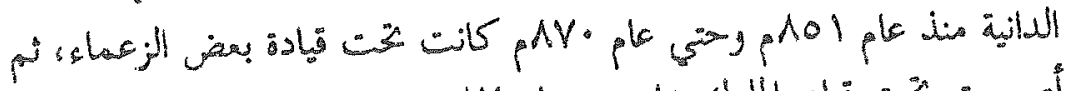

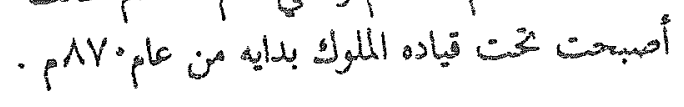

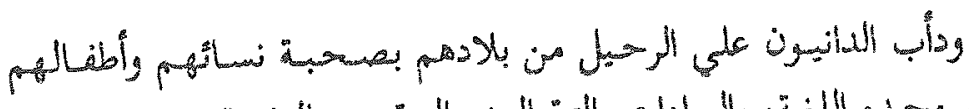

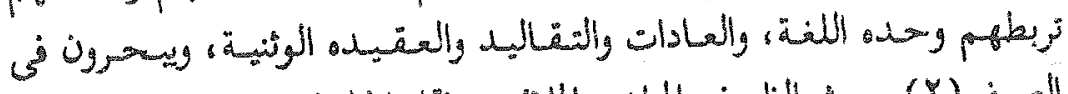

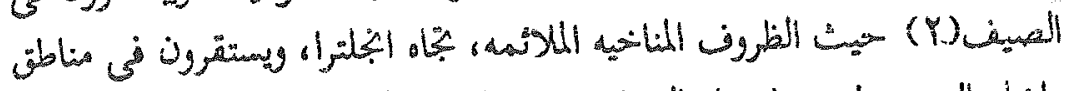

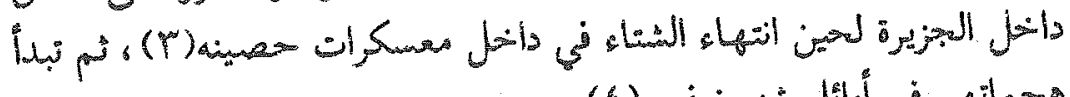

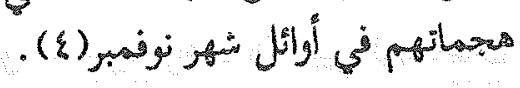

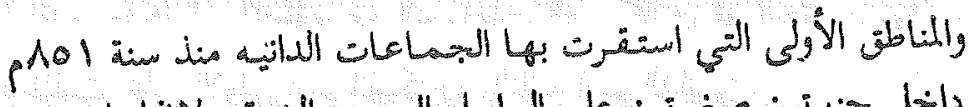

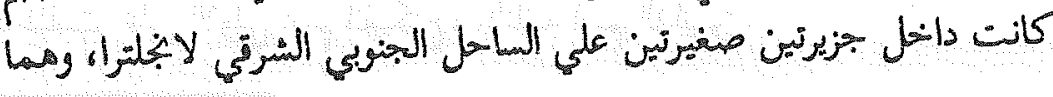

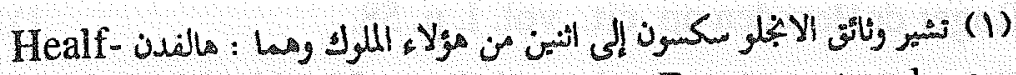
: انظر Bagsecg ulugdene The Anglo Saxon Chronicle, op. cit., Vol. pp. 176 -177, Armold., M.T., Memorials of St. Edmunds Abbey, 2 vol., London, 1882, Vol. I., p.9.

The Anglo Saxan chronicle, op.cit., vol. I, p. 177.

Roger de Hoveden op. cit., vol. I, p 42.

Arnald, M.T., Symeons Monachi Opera, 3 vols, Lon-( $($ ) don, 1882 , vol. III., p. 106. 


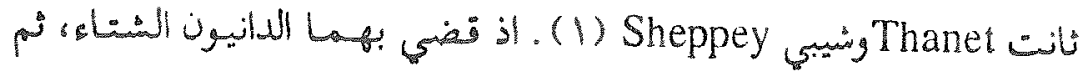

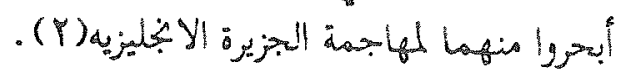

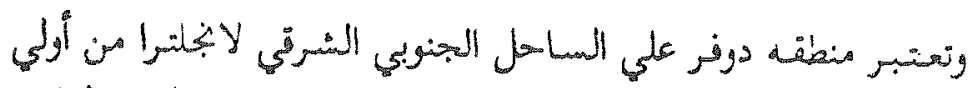

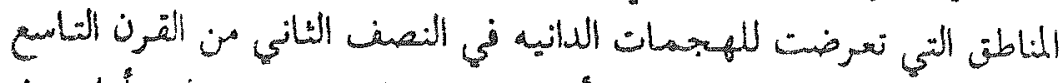

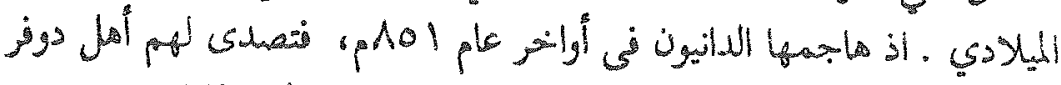

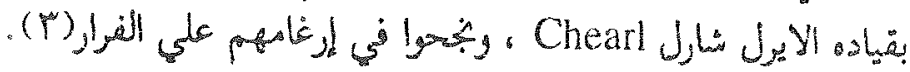

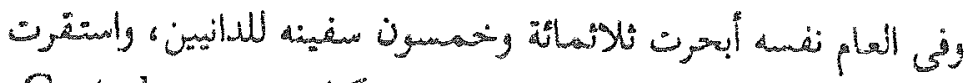

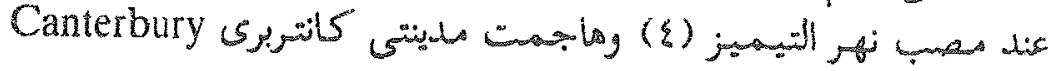

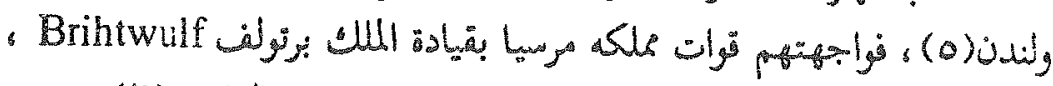

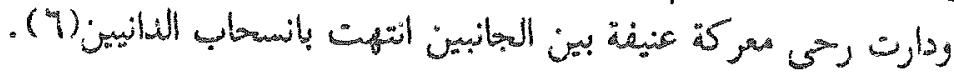

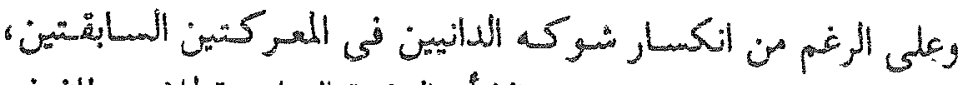

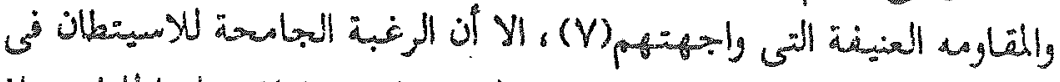

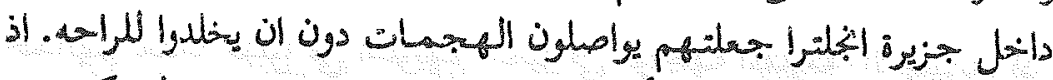

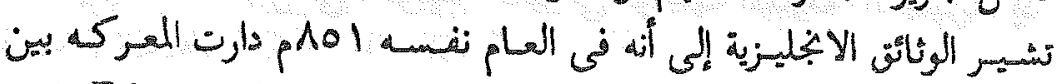

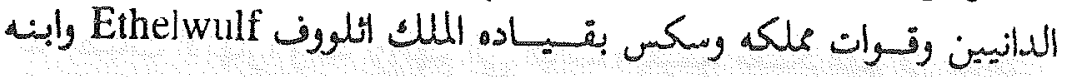

The Anglo Saxan chronicle, op.cit., vol. I, p. 173.

Haskins, H., The Normans in European history New York. 1959, p. 33.

Roger de Hovden. Ibid.

Roger de Hoveden op. cit. vol. 1, p. 41.

The Anglo Saxon Chroniclem op. cit., vol. I, p. 173. (o)

Matthew of westminster, op. cit, vol.I, P. 399.

Oman, C., The Dark Ages (476 - 918), London, 1962, (V) p. 415. 


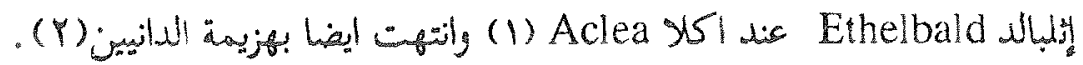

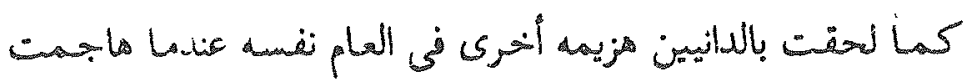

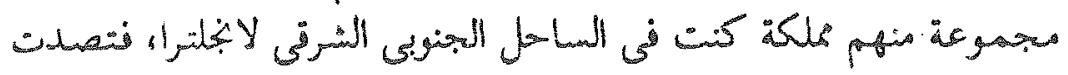

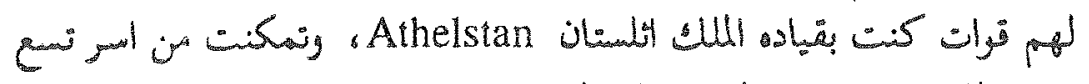

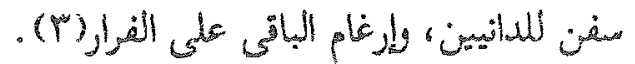

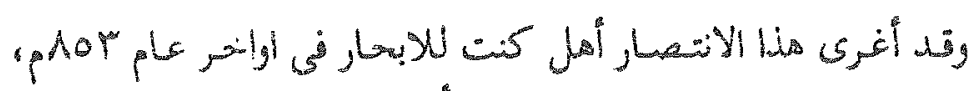

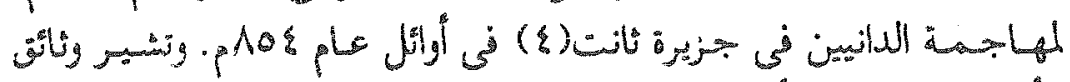

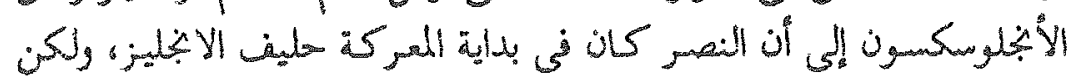

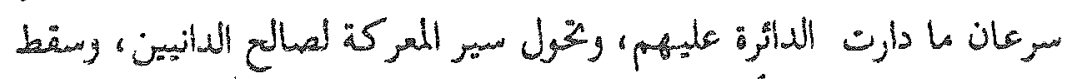

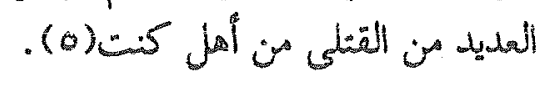

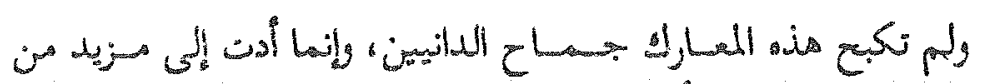

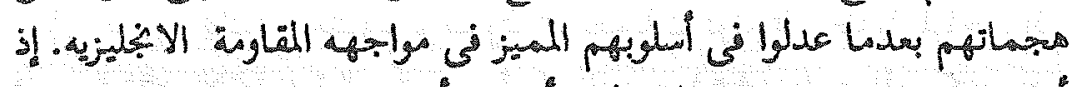

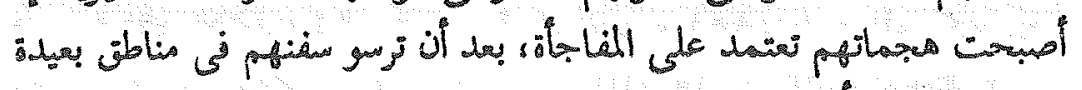

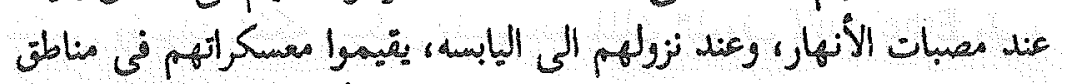

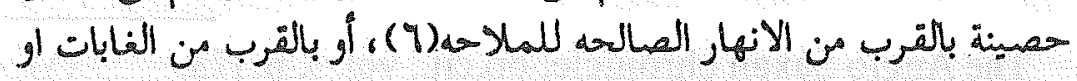
(1) نترف ايفا باسم اوكلى Ockley ، انظر: سعيد عبد الفتاح عانور: المرجع السابق،

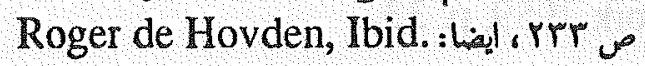

The Anglo saxon chronicle, op. cit pp. 173 - 174.

The Anglo Saxon Chroniclem op. cit., vol. I, p. 173. (r)

Roger de Hoveden, op. cit., vol. I, p. 42.

The Anglo saxon chronicle, op. cit., Vol. I, p. $174 . \quad$ (०)

Stenton, F. M., Anglo - Saxon England, Oxford, 1947, (v)

P. 244. 


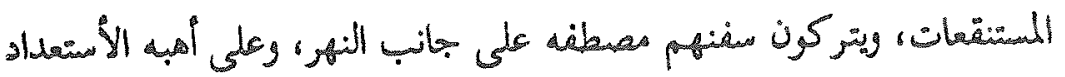
للرحيل السريع(1)

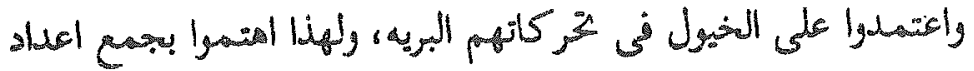

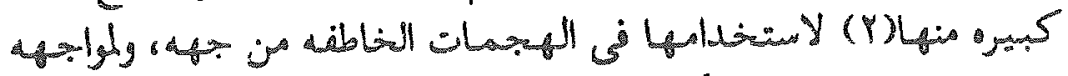

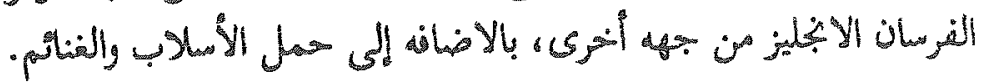

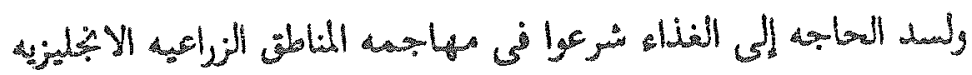

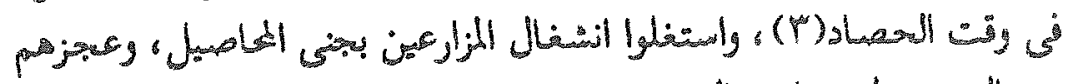

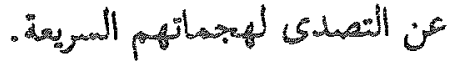

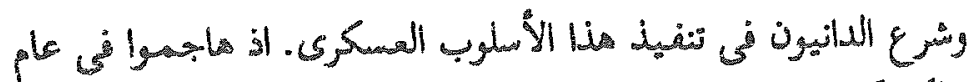

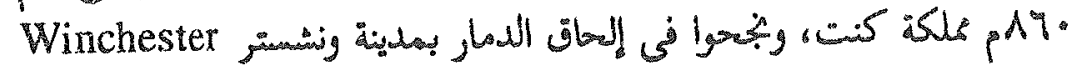

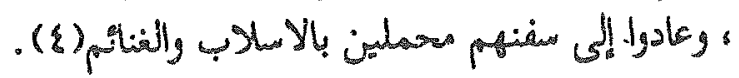

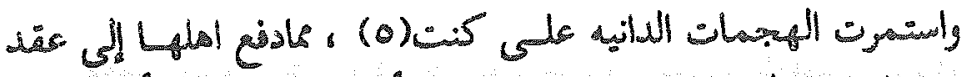

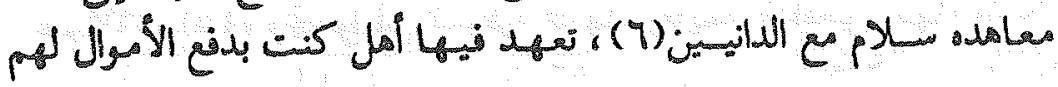

The Anglo Saxon Chronicle, op. cit., Vol. I, pp. 176 186.

Róger de Hoveden, op. cit, vol. I, p. 43.

The Anglo Saxon chronicle, op. cit., vol. I, p. 188.

The Anglo Saxon chronicle, op. cit., 175; Roger de Hoveden, op. cit., ' p. 43.

Matthewof Westminster, op. cit., vol. I, p. 406.

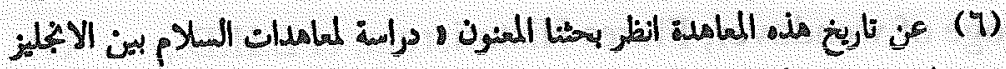

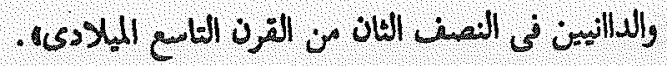




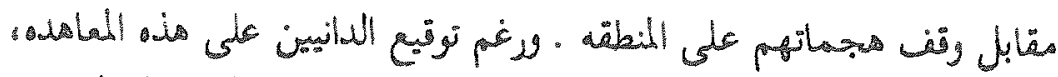

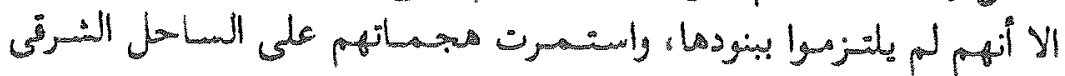

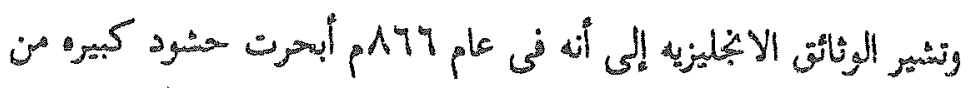

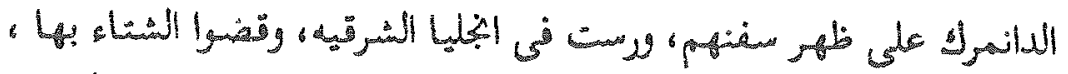

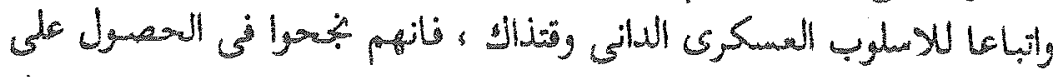

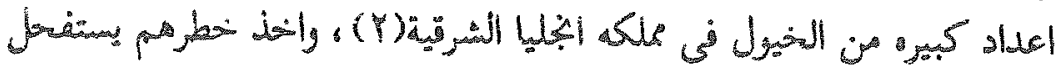

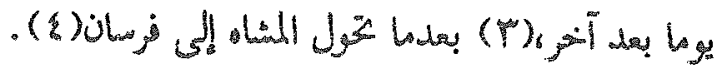

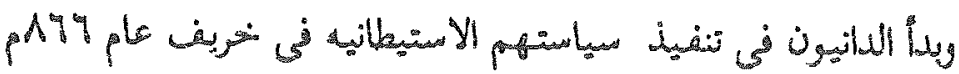

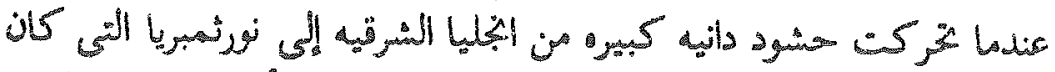

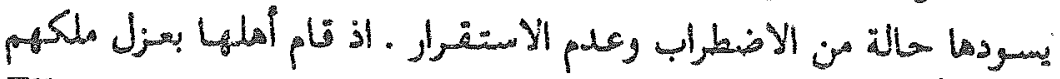
الوسبرت

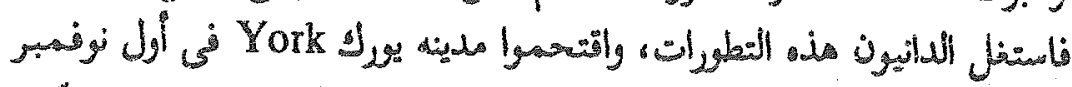

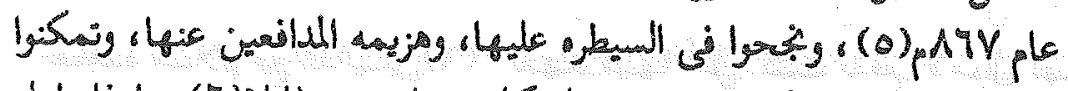

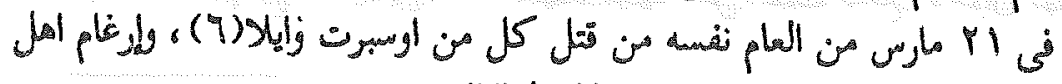

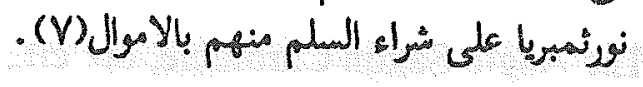

The Anglo Saxon chronicle, op. cit, vol. I,p 176;

(1)

Roger de Hoveden, Ibid;

Matthew of Westminster, op. cit., vol. I, p.407.

The Anglo Saxon Chranicle, op. cit., vol. I, p.176

Haskins, op. cit., p.33.

Mathew ok Westminster, op. cit., Vol. I, p.407

Roger de Hoveden, op,cit, Vol. I, p.44.

Arnold, op. cit, vol. III. p. 106;

Roge of wendover, Flores Historisrum, cf E.H.D., (v) p256.

The Anglo Saxon, Ibid. 


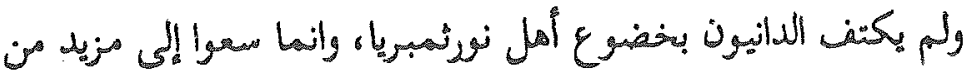

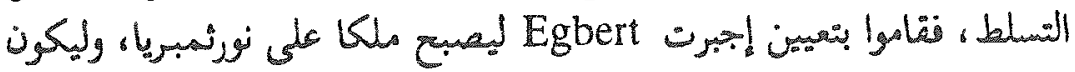

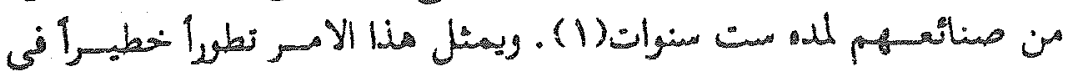

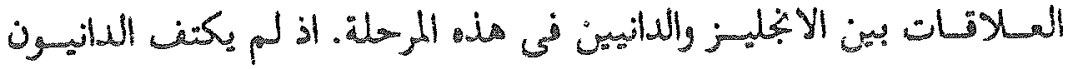

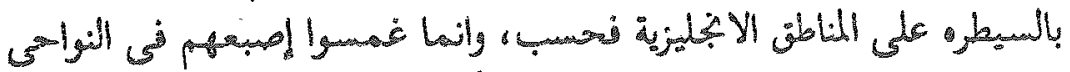

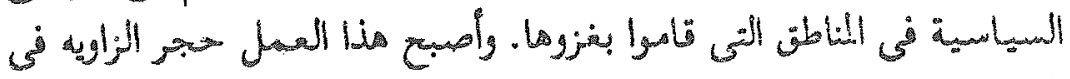

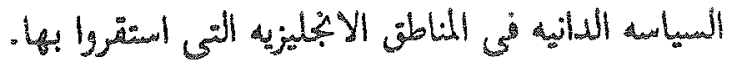

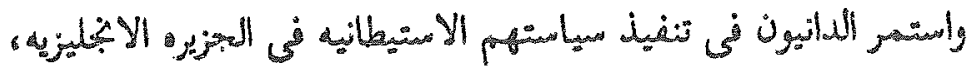

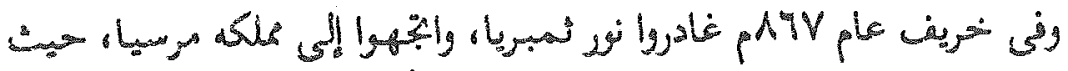

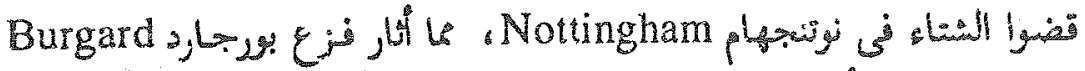

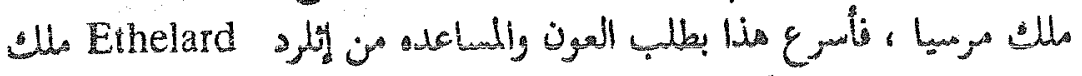

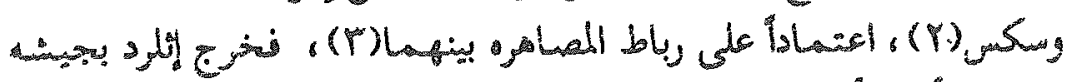

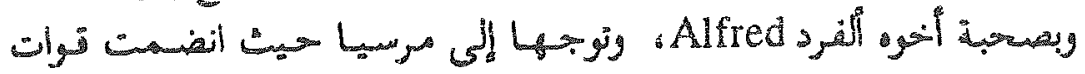
المملكتين استعدادا لملاكاه الدانيين.

ويعد التعاون العسكرى المشترك بين ملكتى مرسيا ووسكس أول تنسيتز

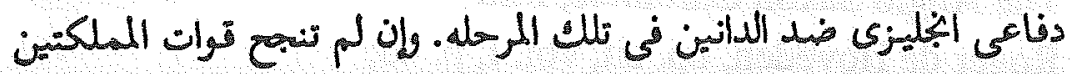

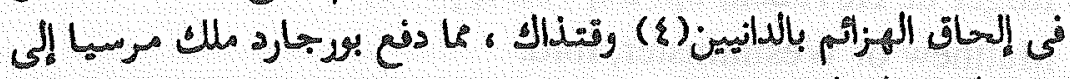

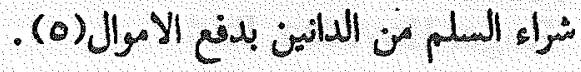

Roger of Wendover, op. cit; p.256.

The Anglo saxon chronicle, op. cit., vol. I, p. 176.

(r)

Stenton, op. cit.,p. 245

The Anglo Saxon Chroniclem op. cit., Vol. I, p. 176

Roger de Hoveden, op. cit., vol. 1, p.44;

(o)

Mattew of Westminster, op. cit., Vol. I, p.409 


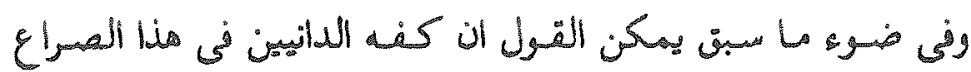

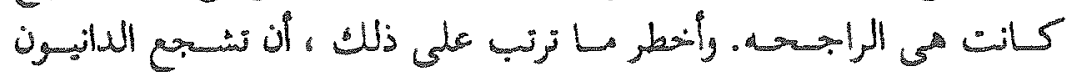

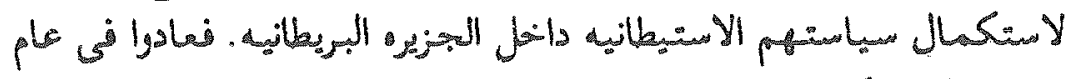

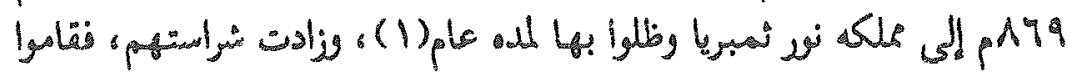

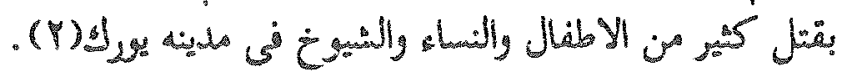

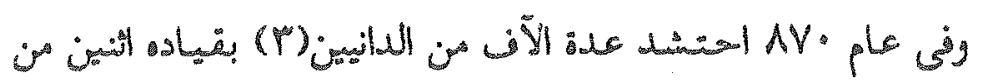

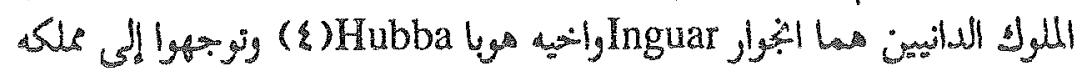

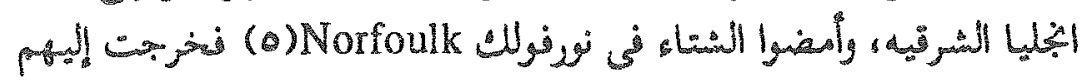

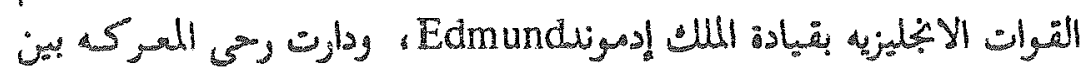

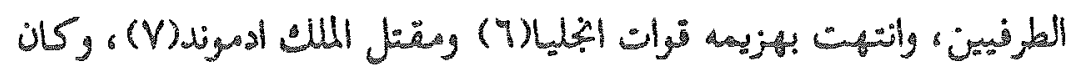

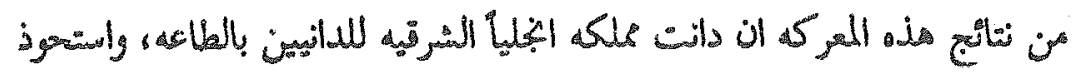

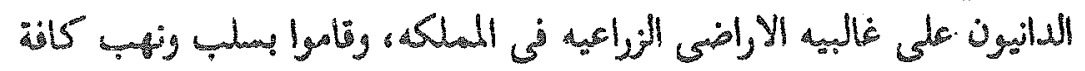

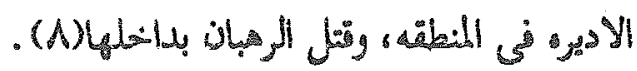

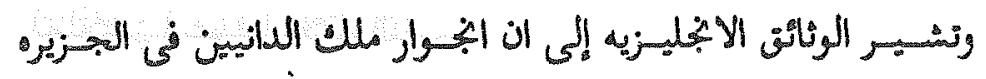

The Anglo Saxon Chronicle, Ibid

Roger de Hoveden, op. cit, vol. I, p. 45;

Matthew of Westminster, Ibid.

Roger Hoveden, Ibid.

Matthew of Westmenoter, op. cit., vol. I, p. 411. 


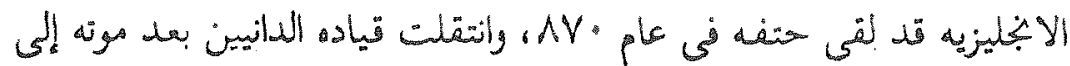
ابنه الملك هالفدن (1) (1)

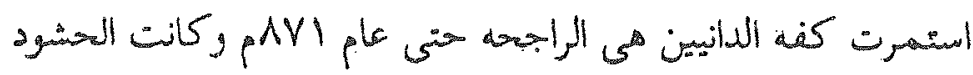

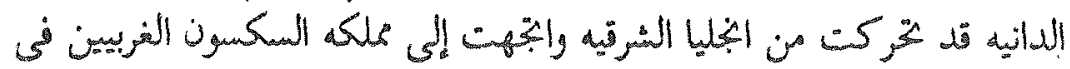

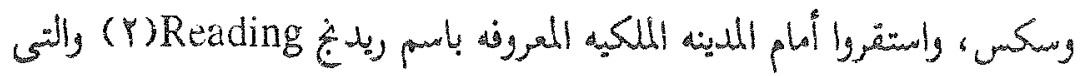

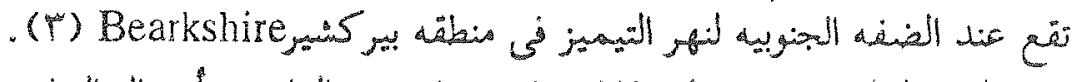

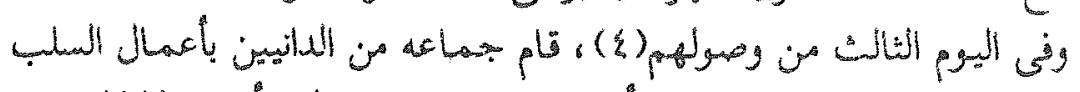

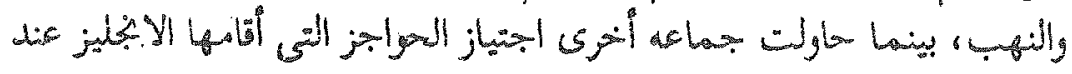

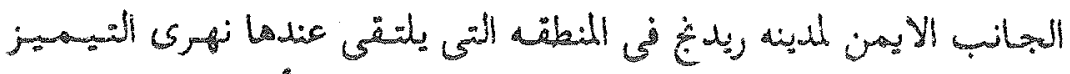

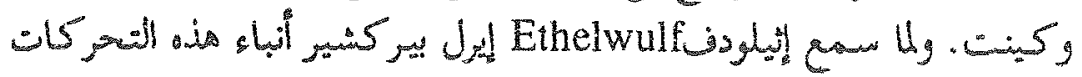

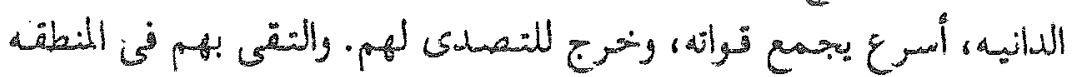

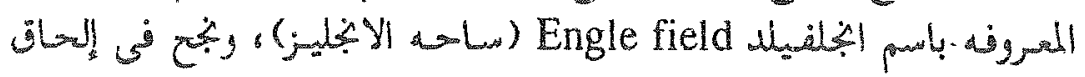

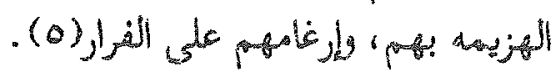

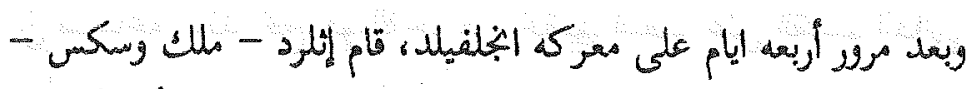

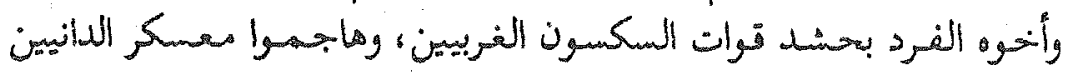

Roger of Wendover, of cit., p. 256;

The Anglo Saxon Chronicle, Ibid,

Matthew of Westminster, op. cit, Vol. I,p.

The Anglo Saxone Chronicle, op. cit, vol. I, p $177 . \quad$ (Y)

Roger de Hoveden, op. cit., vol. I, p. 45.

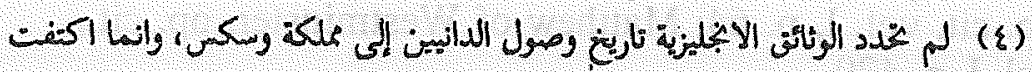

The Anglo Saxon chronicle lbid,

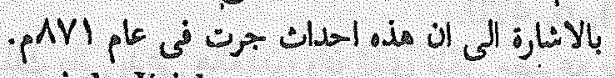

Roger de Hoveden Ibid;

Matthew of Westmnster, op. cit, vol. I, pp.420 - 421 . 


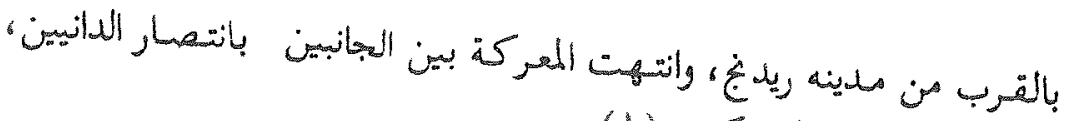

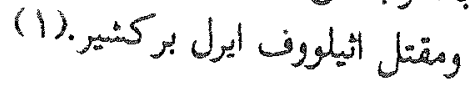

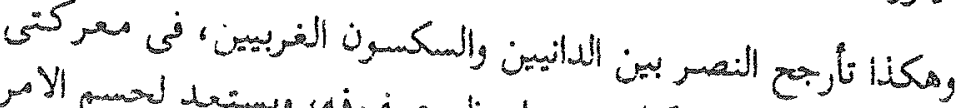

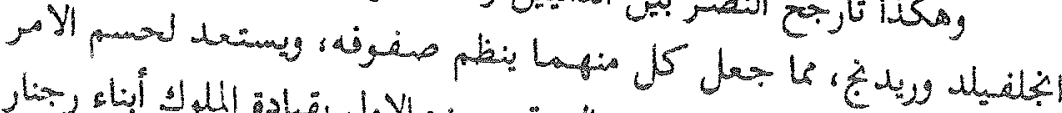

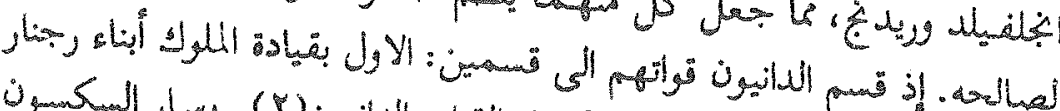

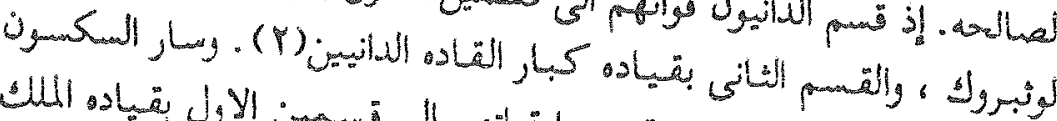

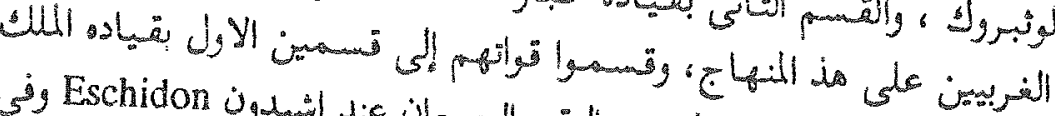

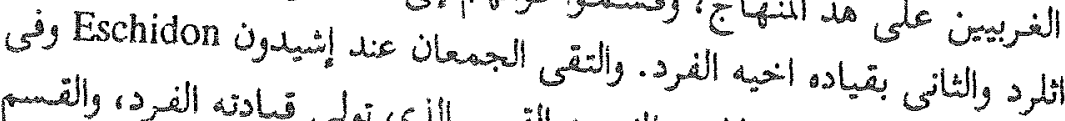

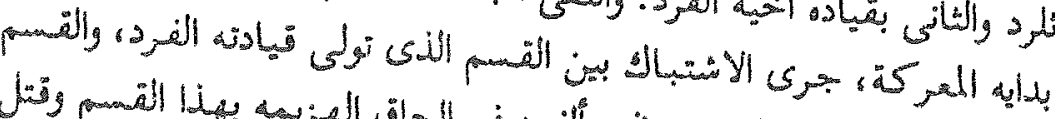

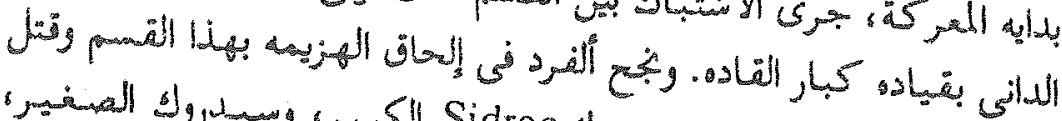

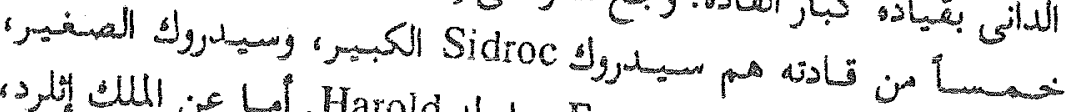

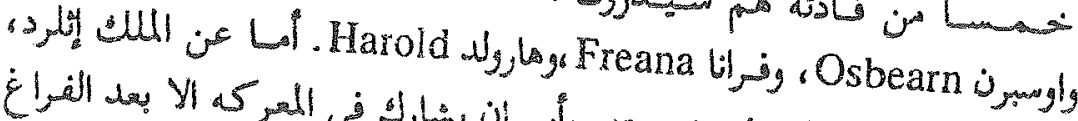

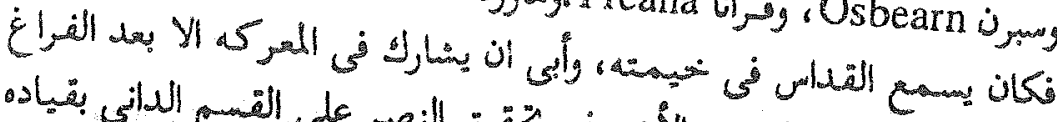

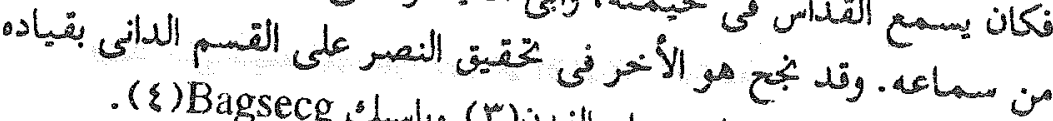

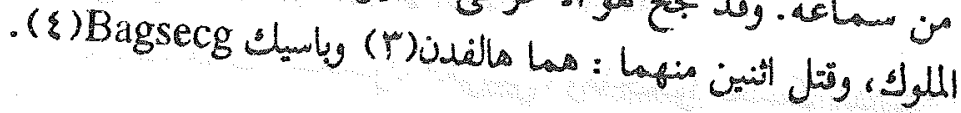

The Anglo Saxon chronicle, op. cit., vol. 1, 177;

Roger de Hoveden, op cit vol Westminster, op. cit., vol I, vol. I, p. 45; Matthew of

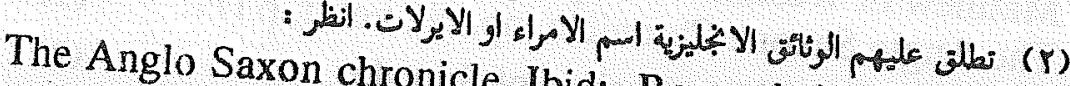
op. cit, vol. I, p. 64; Matthew Ibid; Roger de Hoveden, vol. I, p. 420.

(Y)

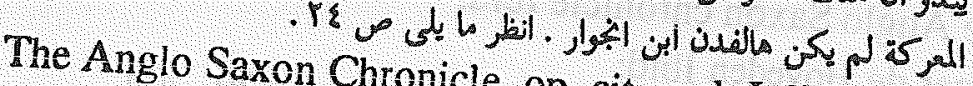
deHoveden, op cit Chronicle, op. cit., vol. I, 177; Roger ( $)$ ster, op. cit, vol. I, p.421. 


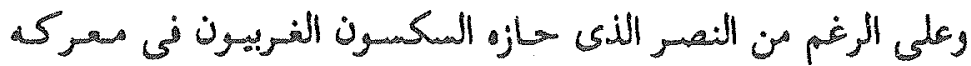

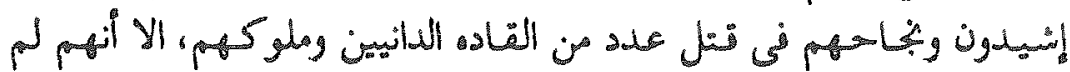

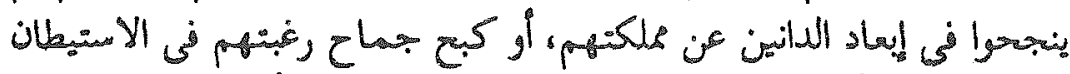

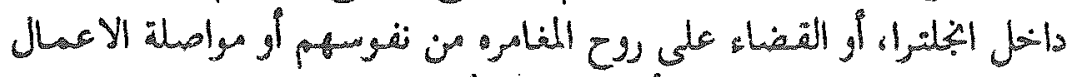

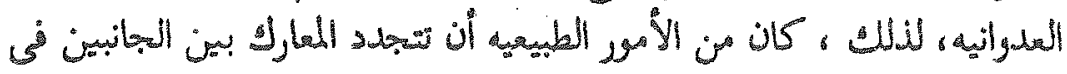

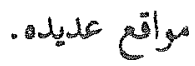

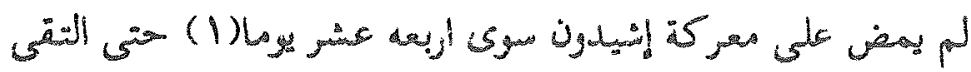

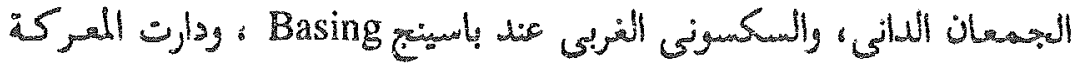

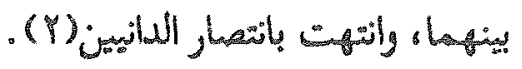

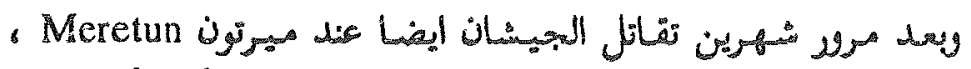

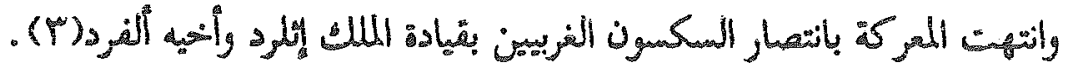

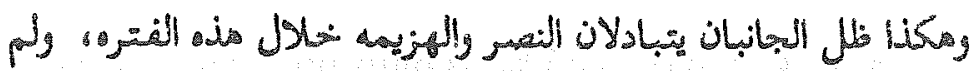

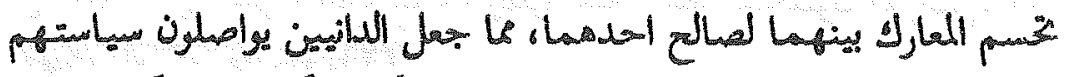

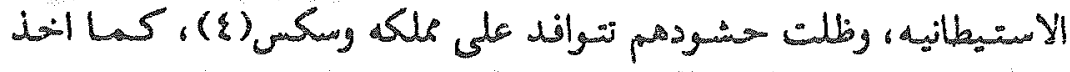

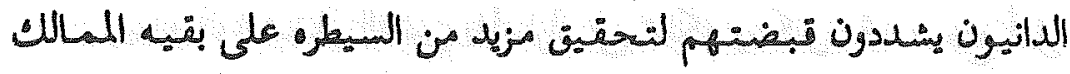
الابجليزيه .

(1) يرى روجر الهوفنلى ان معركة باسينع جرت بعد اربعة ألام من معركة إنبدون أنظر: Roger de Hoveden, op. cit, vol. I, p. 47.

The Anglo Saxin chronicle, op. cit., vol. I, p. 177;

Roger of Wendover, op. cit., p.25̦6; Matthew of Westminster op. cit,, vol. I, p. 421.

The Anglo saxon chronicle, op. cit., vol. I, p. 178; (r)

Matthew of Westminster, op. cit. vol. I, p. 422

The Anglo saxon chronicle, Ibid. 


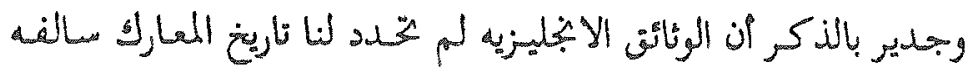

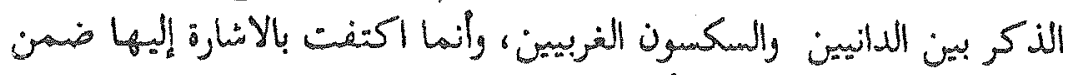

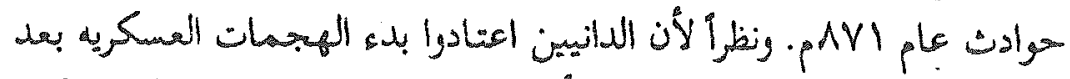

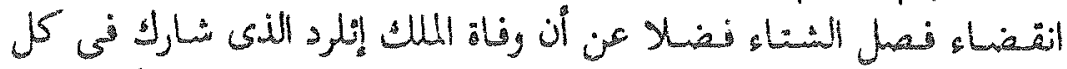

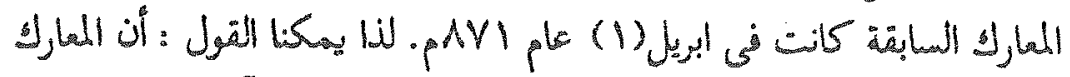

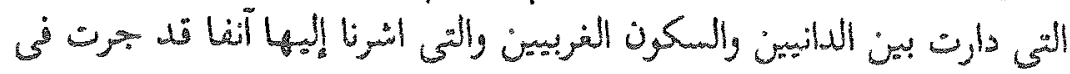
-pAVI ple jigl

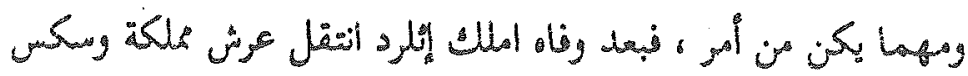

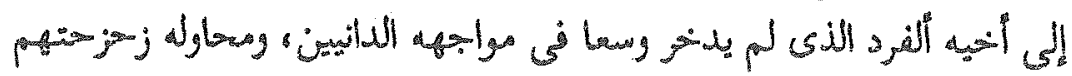

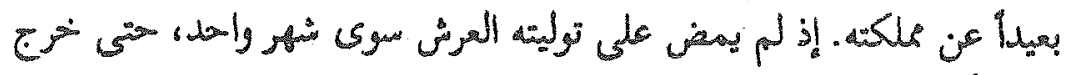

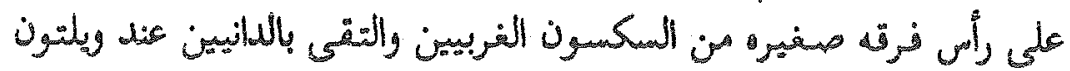
فilton

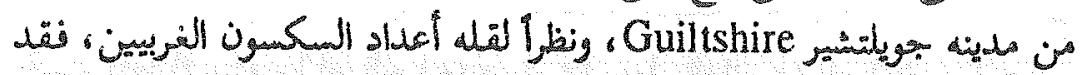

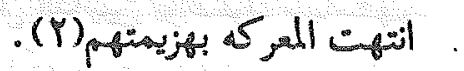

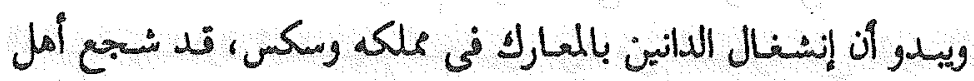

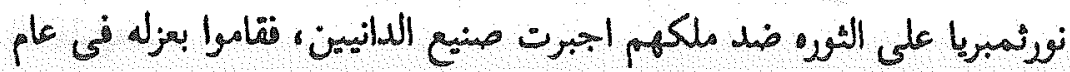

10 (1)

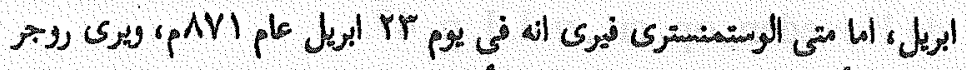

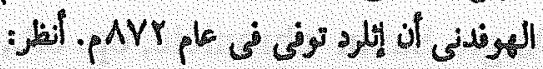

The Anglo Saxon chronicle, op. cit., vol. 1, p. 178; Matthew of westminster, op - cit., vol. I, p. 422; Roger de Hoveden, op., cit., vol. I, p.47.

The Anglo Saxon chronicle, op. cit., vol. I, p. 178;

Roger de Hoveden, op. cit., vol. I, p. 48. 


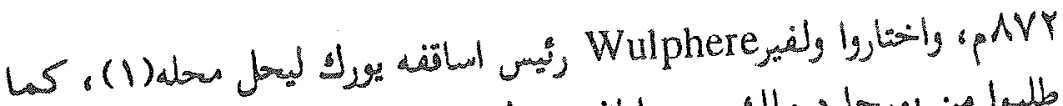

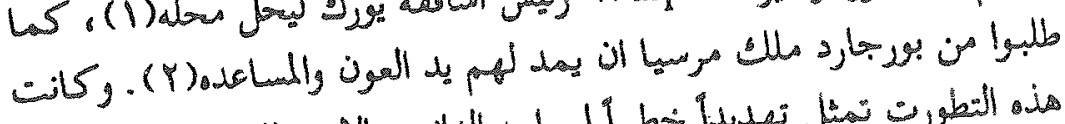

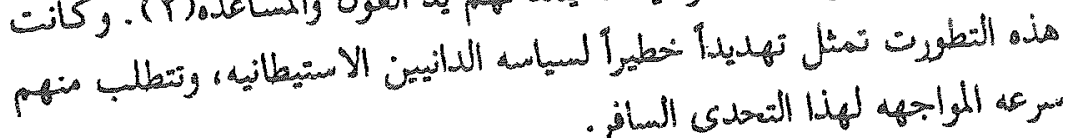

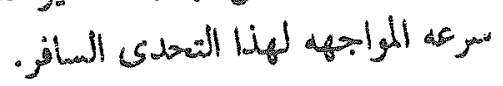

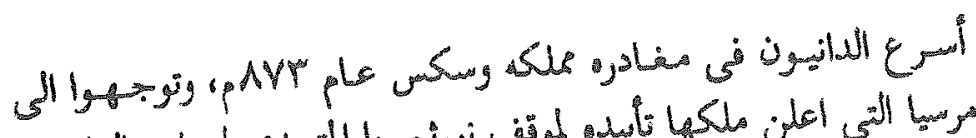

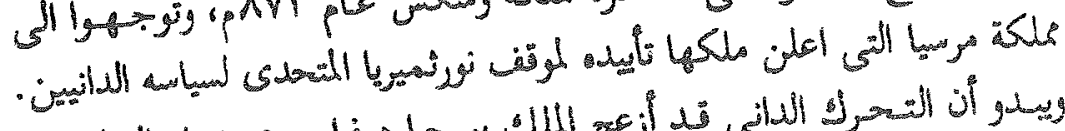

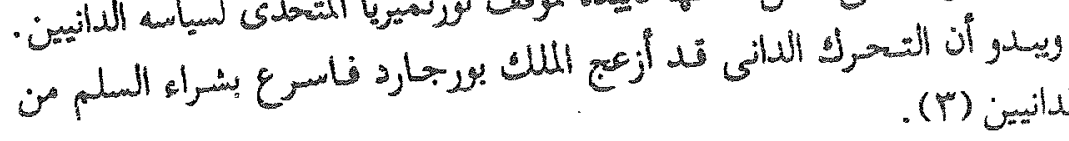

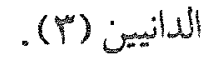

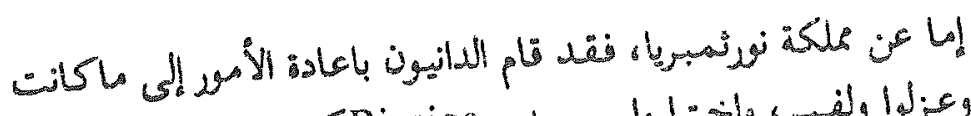

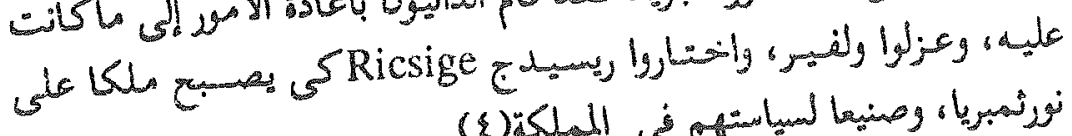

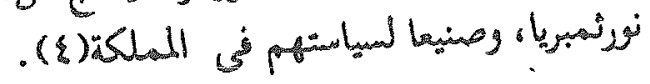

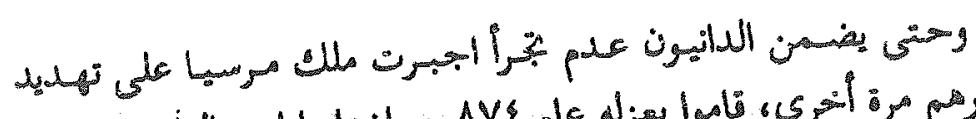

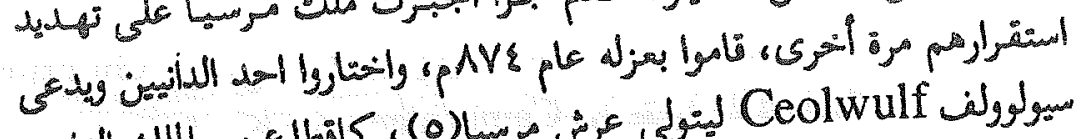

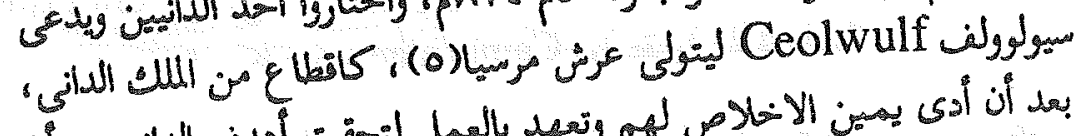

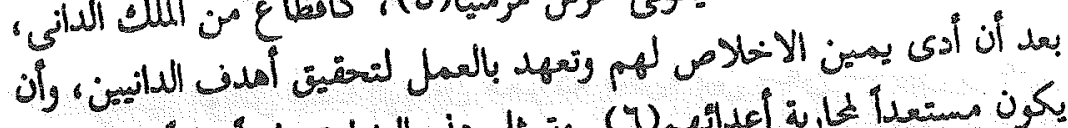

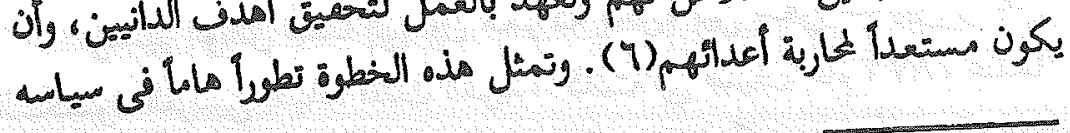

The Anglo Saxon chronicle, Ibid;

Roger of Wendover, op. cit., p. 256.

The Anglo Saxon Chronicle, op. cit., vol. I, p. 178; (Y)

Roger de Hoveden, op. cit., vol. p. 48.

Roger of Wendover, op. cit., p. 256;

Roger e Hoveden, Ibid.

The Anglo Saxon chronicle, Ibid. 


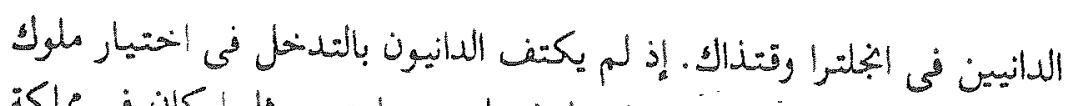

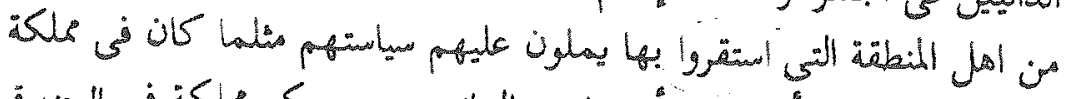

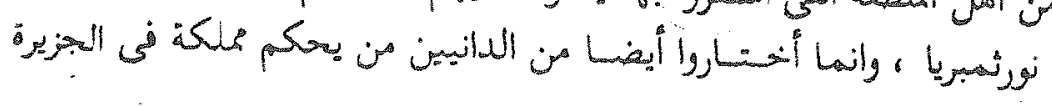

البريطانية.

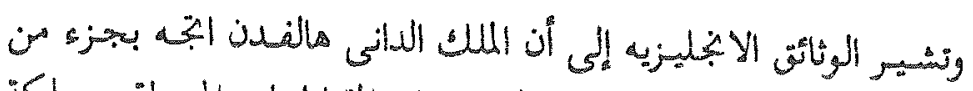

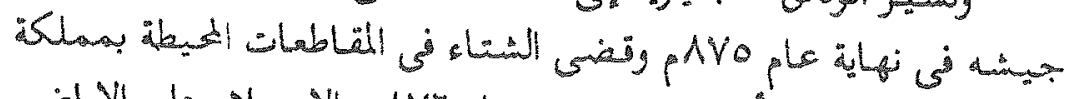

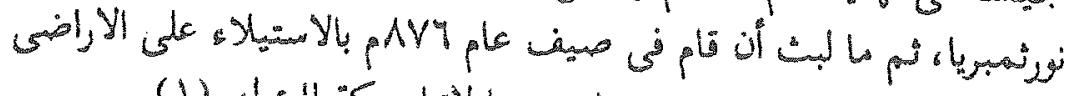

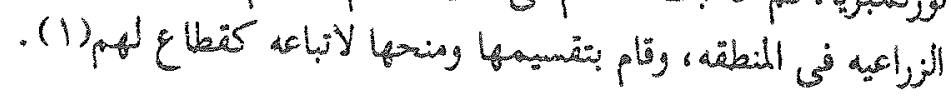

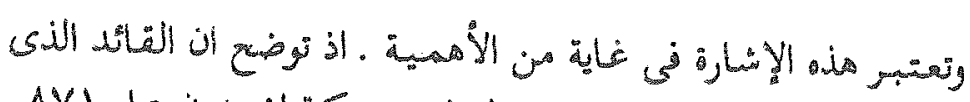

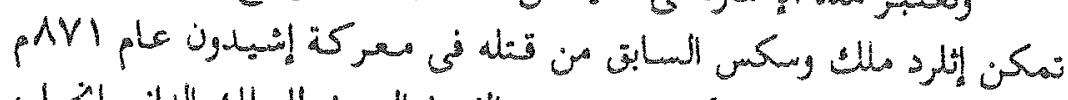

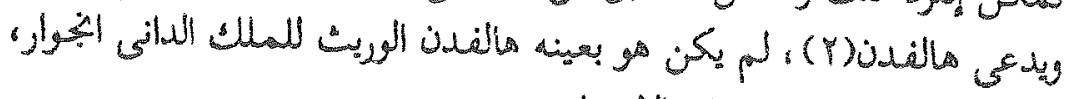

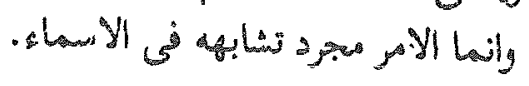

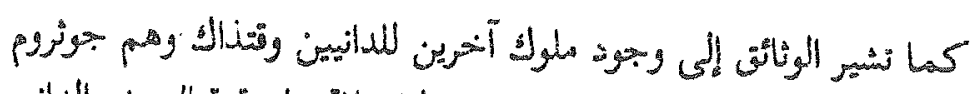

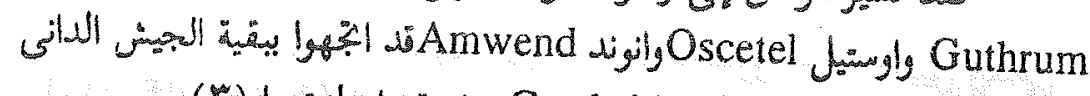

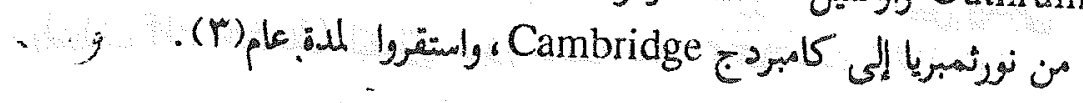

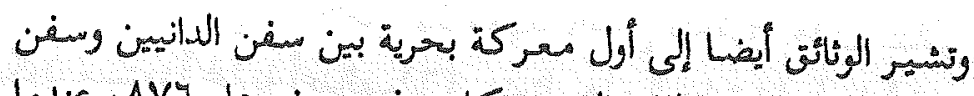

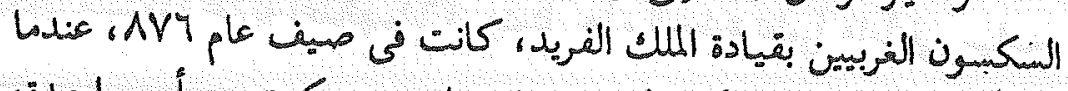

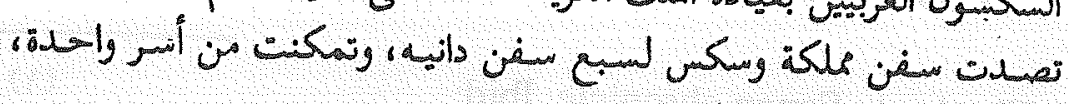

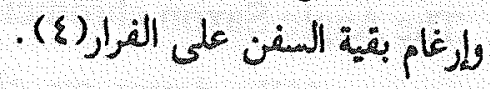

The Anglo Saxon Chronicle, op. Cit., Vol. p.178;

(1)

Roger of Wendover, op. cit, p. 256;

Matthew of westminster, op. cit. vol. I p. 427.

The Anglo saxon chronicle, op. cit., vol. 1, 178. ) انظر ما سيق ص 19.

Roger of Wendover, op. cit, p. 256.

The Anglo Saxon chronicle, Ibid. 


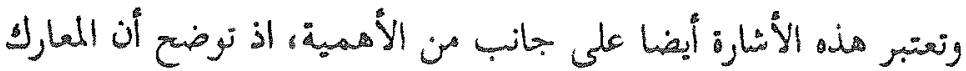

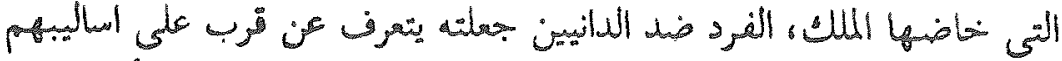

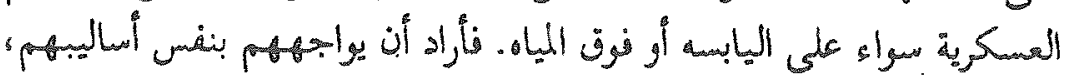

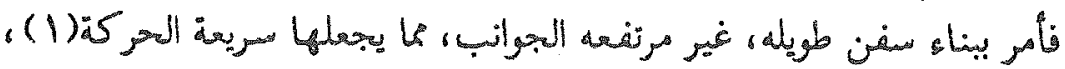

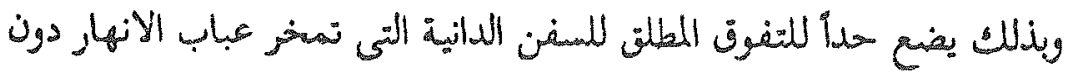
- (Y)änglio

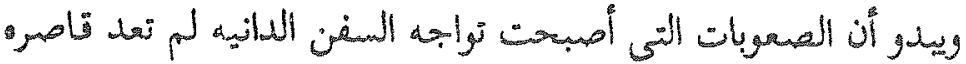

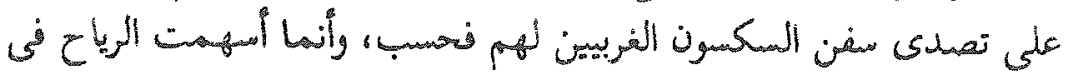

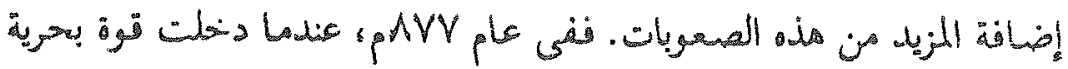

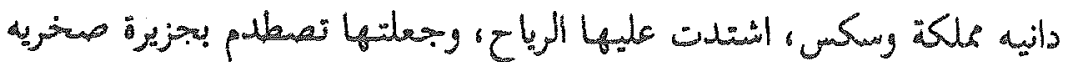

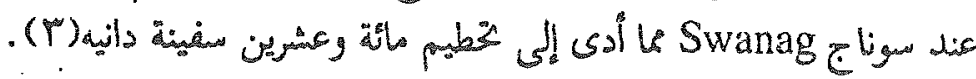

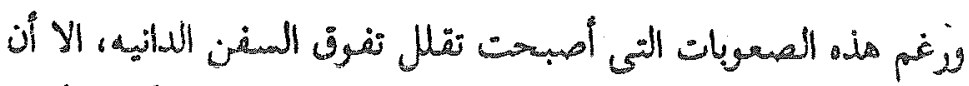

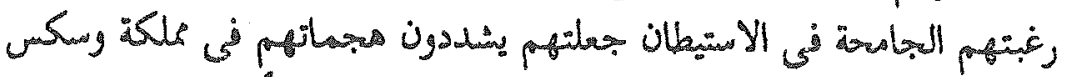

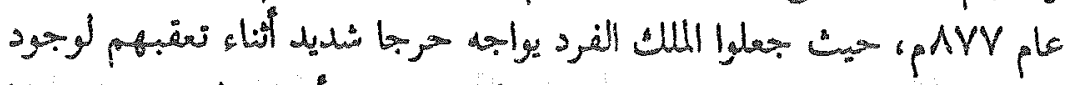

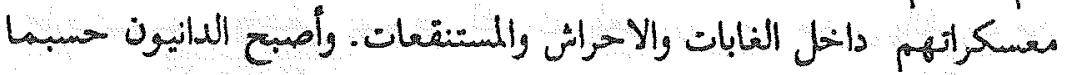

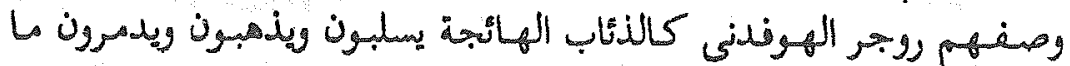

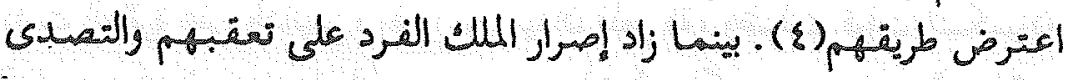

Roger de Hoveden, op. cit, vol. I, p. 58;

Matthew of westminster, op. cit, vol. I, p428.

Trevelyan, op. cit, p.77.

The Anglo Saxon Chronicle, op.. cit., vol. I, p.179.

Roger deHoveden op. cit., vol. I, p. 49;

The Anglo Saxon Chronicle, Ibid. 


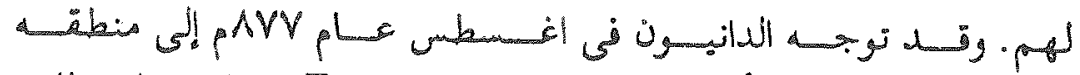

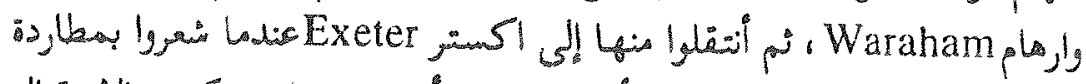

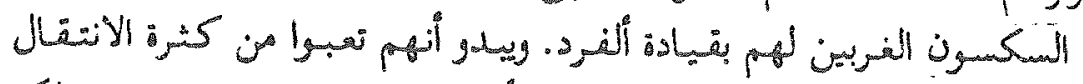

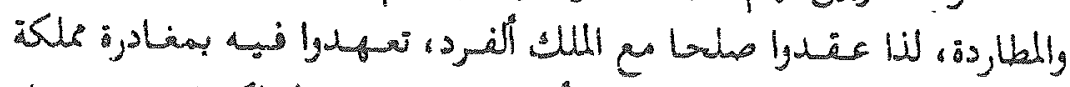

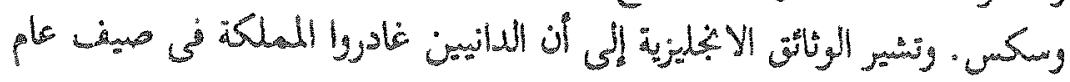

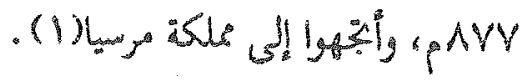

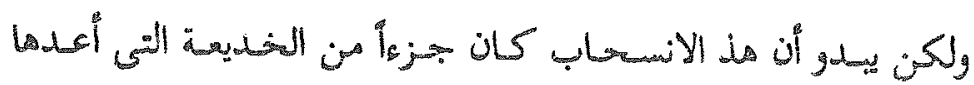

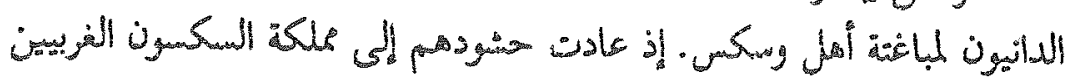

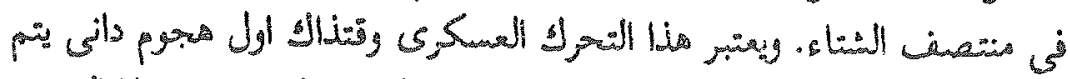

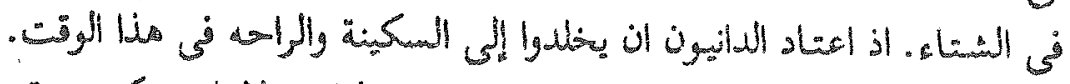

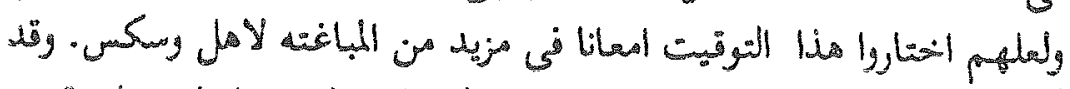

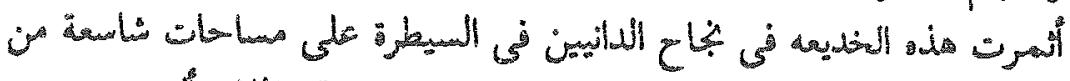

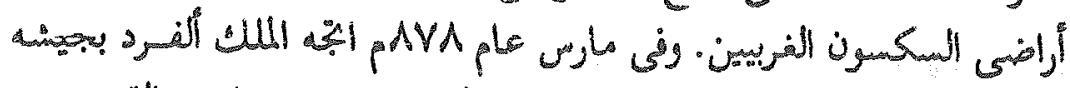

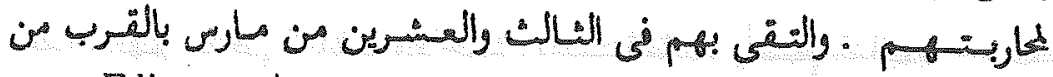

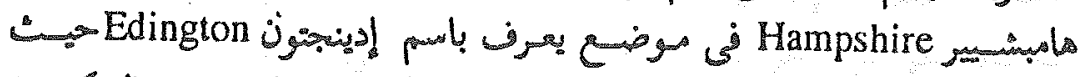

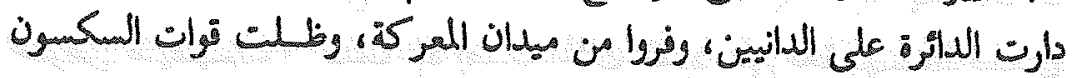

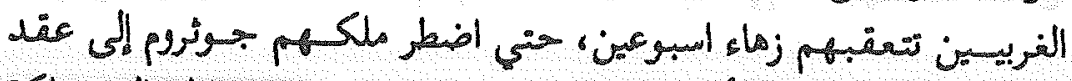

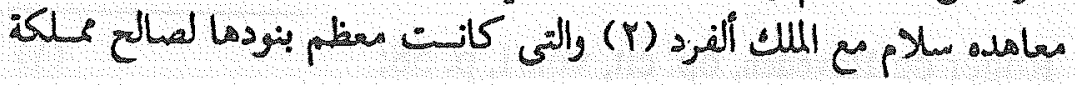

The AngIo Saxon Chronicle, op. cit., vol. I, p. 179; (I)

Roger de Hoveden, op. cit., vol. I, p. 49;

Matthew of Wesiminster, of. cit. vol. I,p.428.

The Anglo Saxon Chronicle, op. cit., vol. I, p. 180; (Y)

Roger de Hoveden, op. cit, vol. I, p.50;

Matthew of Westminster, of. cit. vol. I,pp.430-433. 


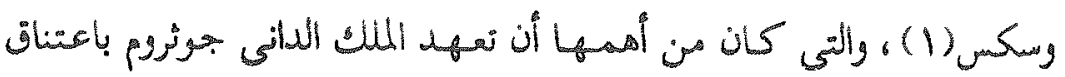

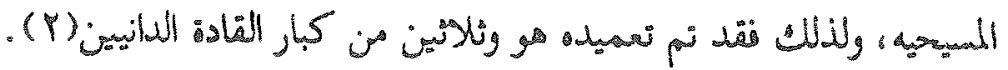
وكان من نتائج هذه المعاهدة أن توتفت الأنسباكات العسكرية البرية

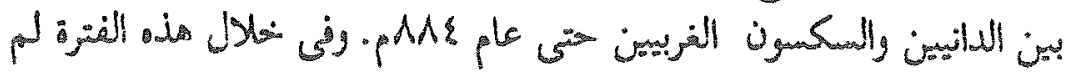

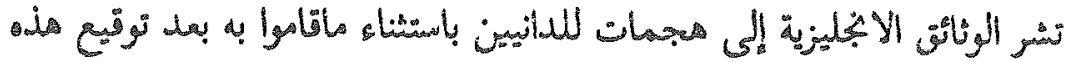

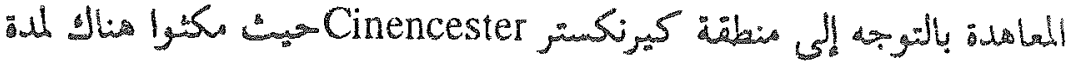

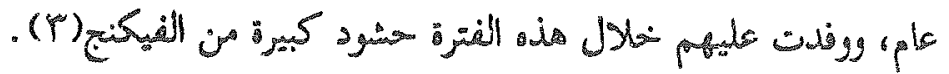

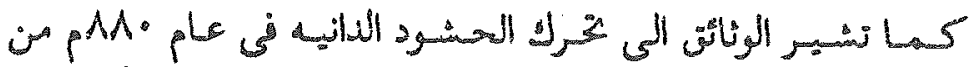

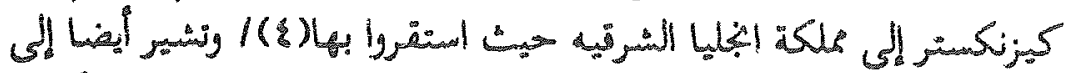

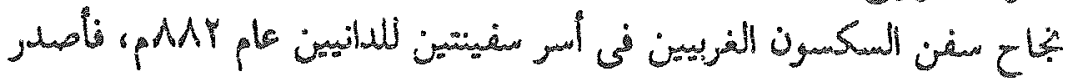

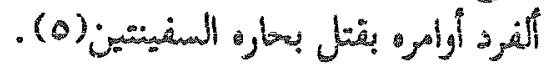

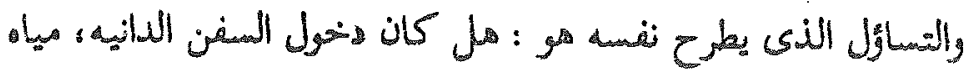

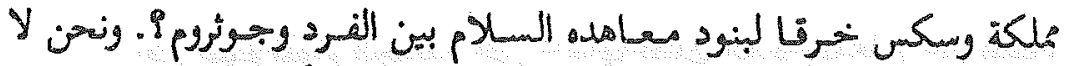

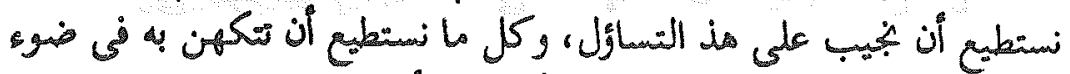

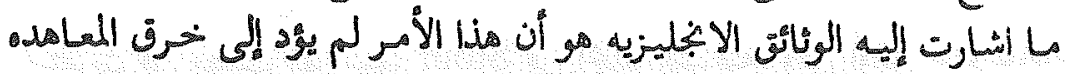

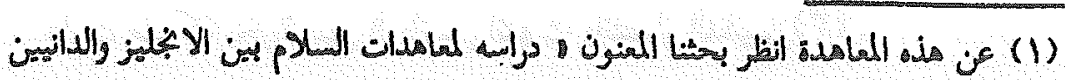

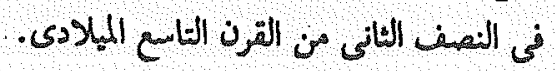

Rayner, R. M., Aconsise history of Britain, London, (V) 1939, p.16.

The Anglo Saxon chronicle, op. cit, vol. I, p. 180;

Roger de Hoveden, op. cit, vol. I, p.50.

The Anglo Saxon Chroniclem op. cit, vol. I, p. 181.

Roger de'Hoveden, op. cit., vol. I, p.51;

The Anglo Saxon Chronicle, Ibid. 


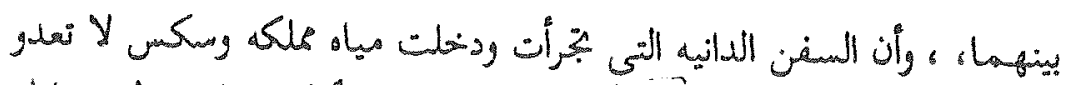

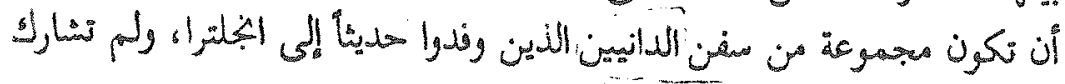

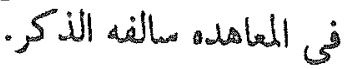

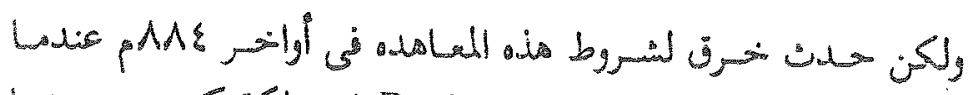

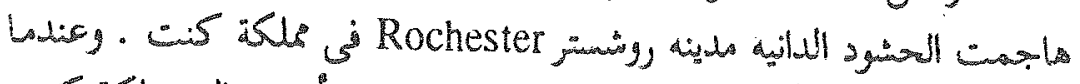

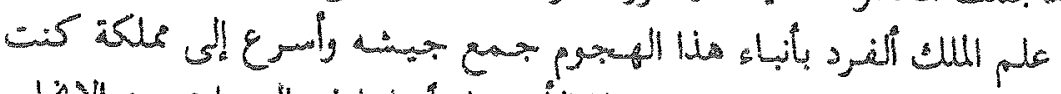

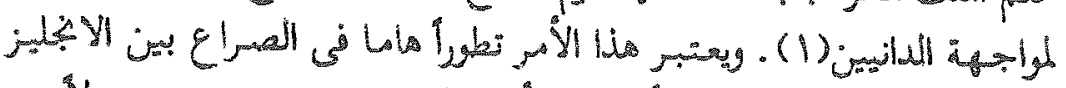

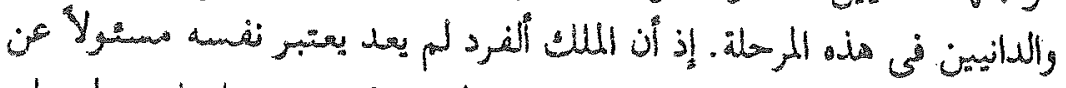

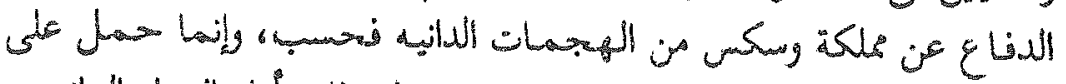

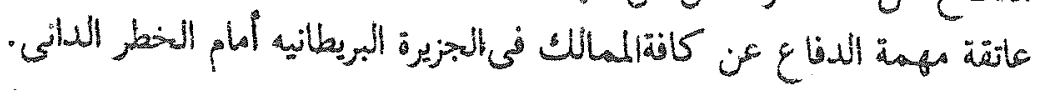

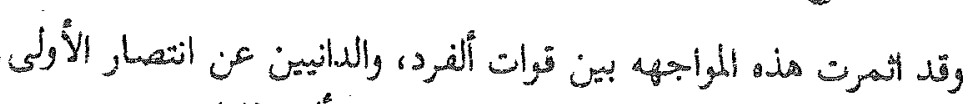

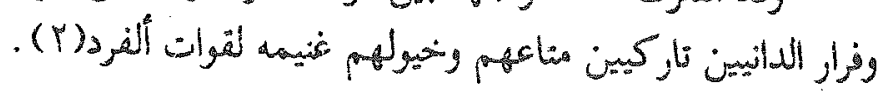

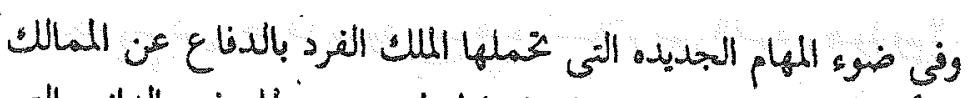

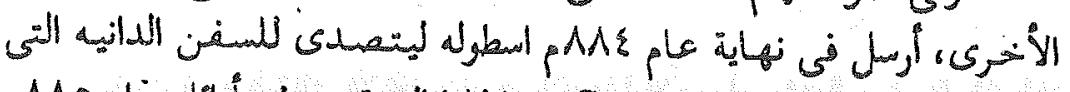

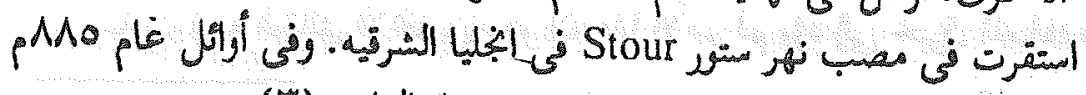

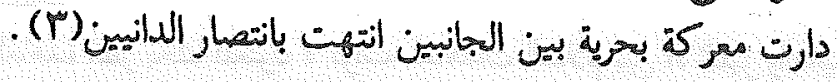

The Anglo Saxon Chronicle, op. cit., vol. I, p.181;

Roger de Hoveden, op. cit, vol. I, p. 55;

The Anglo Saxon Chronicle, op. cit., vol. I, p182.

he Anglo Saxon Chronicle, op. cit., vol. I, p.182;

Roger de Hoveden, op. cit., vol. I, p.55;

Matthaiv of Westminster, op. cit., vol. I, p. 451. 


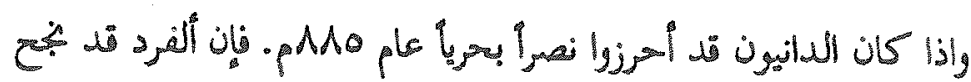

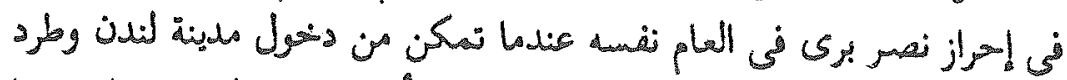

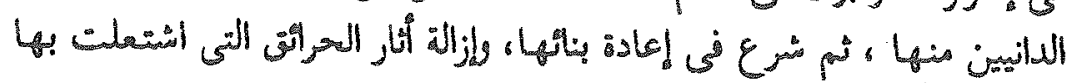

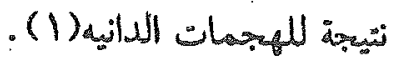

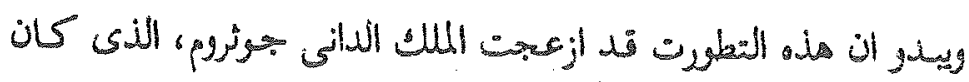

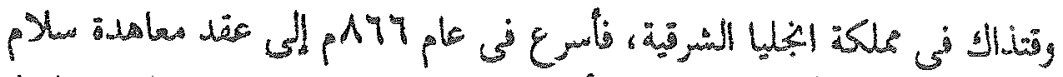

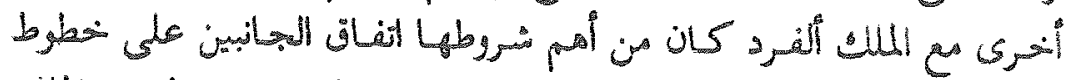

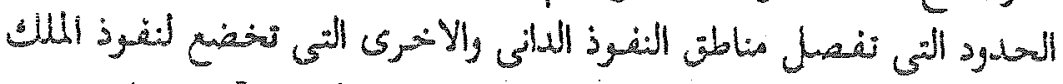

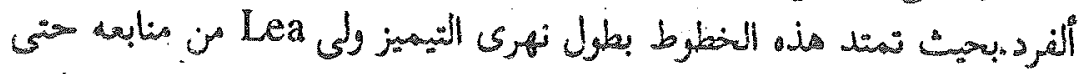

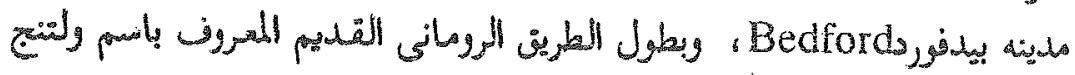

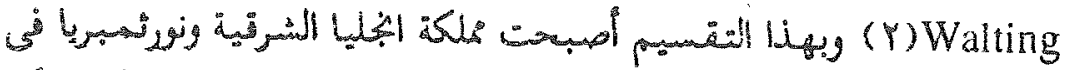

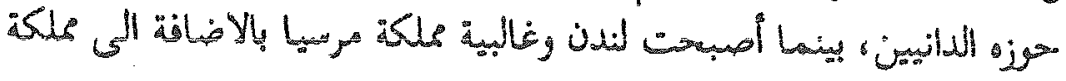

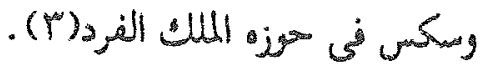

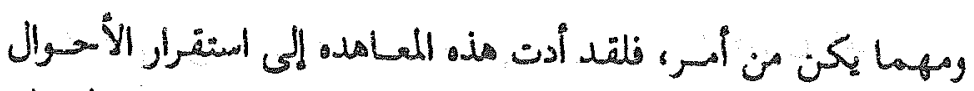

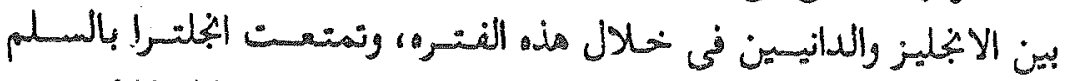

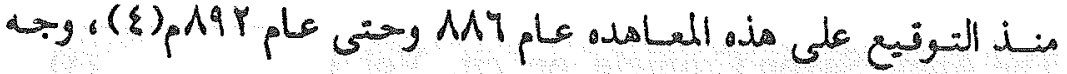

The Anglo Saxon Chronicle, op. cit., vol, I, p.183.

The Anglo Saxon Chronicle, op. cit, vol. I, p 182;

The treaty between Alfred and Guthrum (886), cf. E.

H,D., pp. 380 - 381; Also:

Louis, L. S., Basic Documents in Medieval history, New York, 1959, pp. 39-40.

Stenion, op. cit., p258.

$$
\text { مسيد عبد النتاح عاشور : المرجع السابن، ص rro - rro }
$$




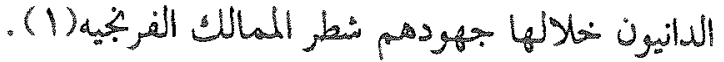

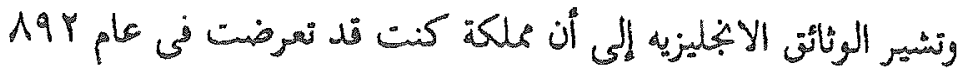

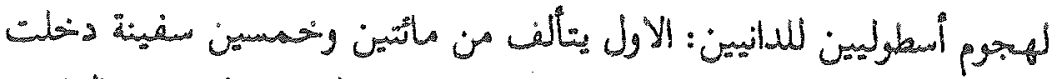

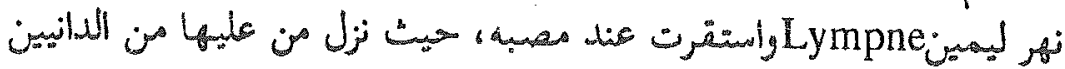

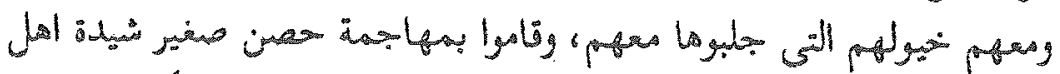

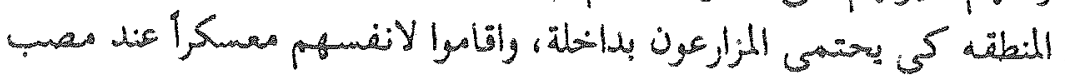

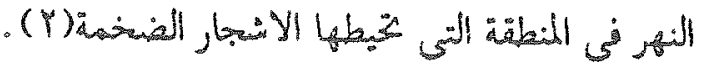

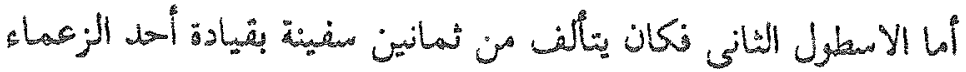

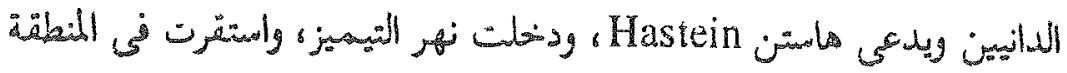

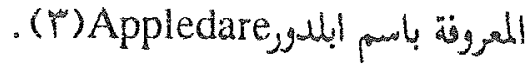

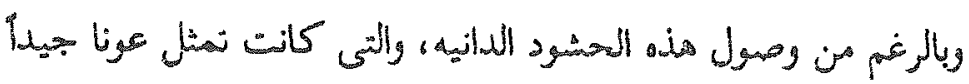

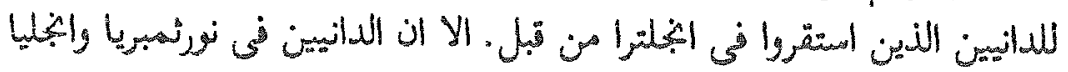

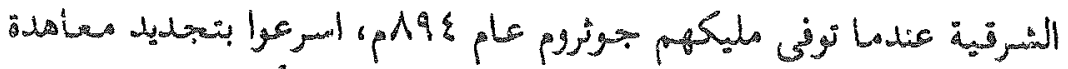

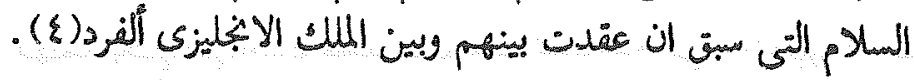

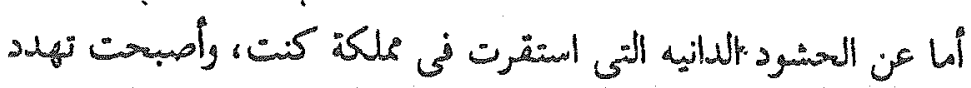
The Anglo Saxon Cronicle, op. cit., Vol. I, pp. 183-184.

The Anglo Saxon Chronicle op. cit., vol. I,p. 184; (r) Matthew of Westminster, op. cit., vol. I, p447.

The Anglo Saxon Chronicle, Ibid,

Roger de Hovden, op cit., vol. I, p.58.

The Anglo Saxon Chronicle, op. cit, vol. 1, p.185;

Roger de Hoveden, Ibid.

Matthew of westminster, op. cit. vol. I, p.448. 


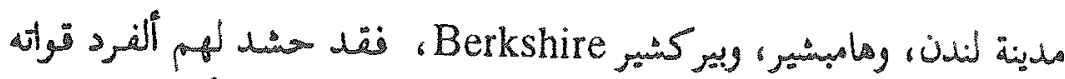

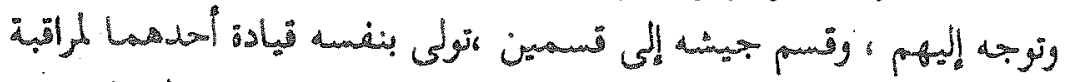

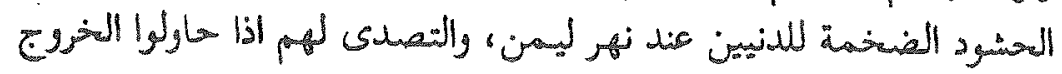

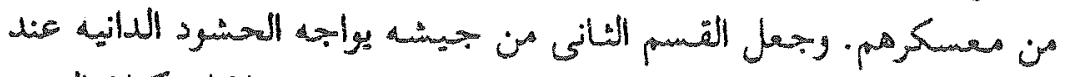

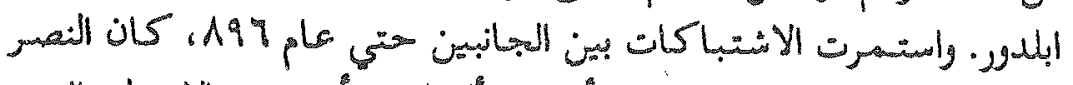

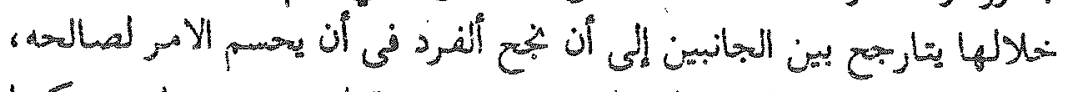

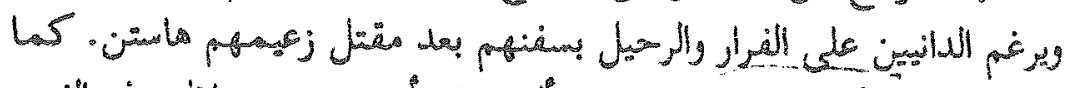

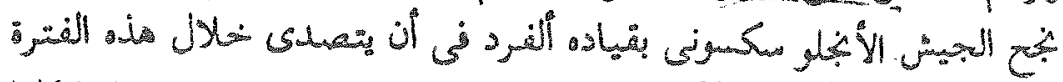

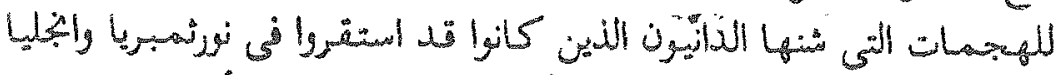

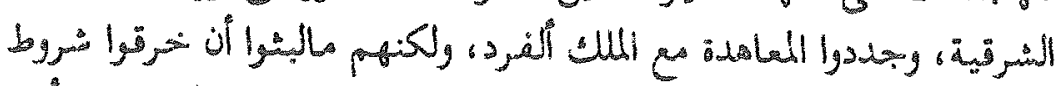

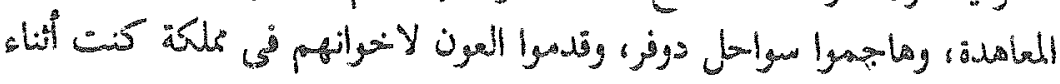

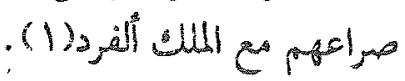

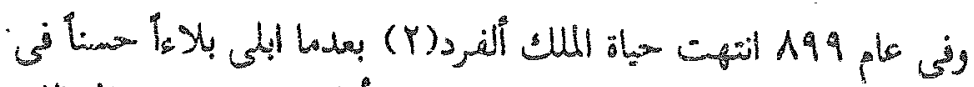

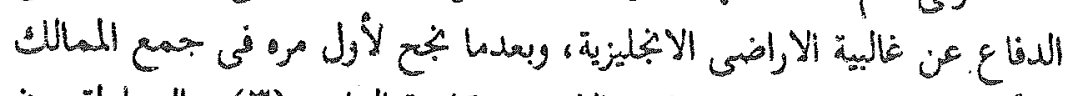

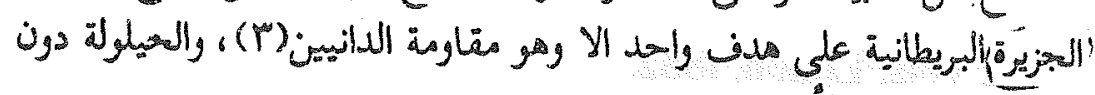

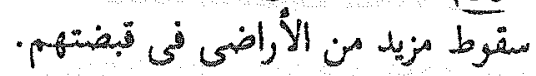

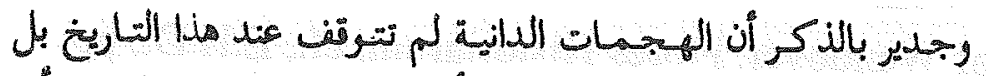

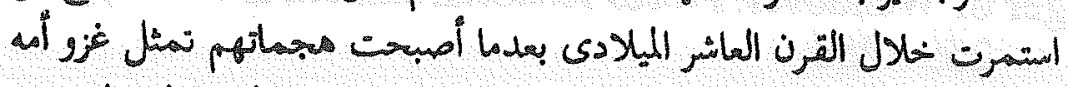

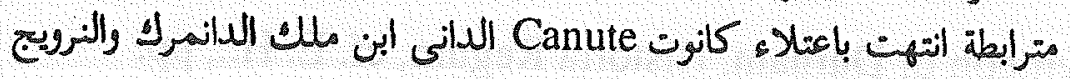

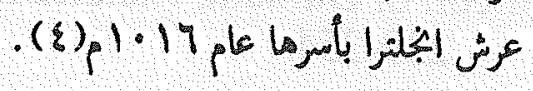

The Anglo Saxon Chronicle, op. cit., vol. I, pp.185-189, (1) Roger de Hoveden, op. cit., vol. I, pp. 58-59;

Matthew of Westminster, op. cit., vol. I, pp. 449-452.

The Anglo Saxon Chronicle, op. cit., vol. I, pl89;

Symeon of Durham, Historia Regum, ef . E. H.D., op. cit., p251.

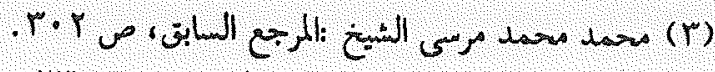

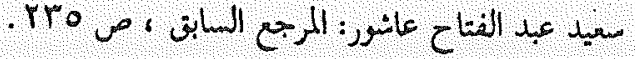




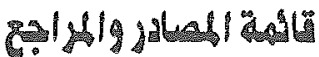

\section{: الإهية}

-Annals of St. Bertins, cf. English historical Documents (E.H.D.), Lonon, 1968, pp. 314-318.

-Anglo Saxon Chronicle, cf. E.H.D., pp.135-235.

-Asscr, The lige of king Alfre, ed. by W.H. stevenson, Oxford, 1904.

- Letter of pope John VIII to Ethelar archlichop of Canterbury, cf. E.D. p. p.811.

-Mattew of Westminster, The Flowers of history, 2 vols, Lonon, 1853.

-Memorials of St. Edmund's Abley, ed. by M.T. Arnold, 2 vols, Lonon, 1882.

-Roger deHoveden, The Annals, 2 vols., London, 1853.

-Roger of Wendover, Flores Historiarum, cf., E.H.D., pp. $255-258$.

-Symeon of Durham, Historia Regum, cf. E. H.., pp.

239-254.

-Symeons Monashi opera, ed. by M. T. Arnald, 3 vols, London, 1882.

-The Treaty between alfred and Guthrm (886), cf. E.H.. pp.380 - 381.

-Whitelock, D., Saga book of the vinking society, Lonon, 1954. 


$$
\text { ثانيا :المرا-مع الأجنبيهة : }
$$

Haskins, H., The Normans in European history, New York, 1959.

Koenigsberger, H. G., Medieval Europe (400 - 1500), New York, 1987.

Louis, L.S., Basic Documents in Medieval history, New York, 1959.

Morris, B., The Middle Ages, New York, 1983.

Oman, C., The Dark Ages (476 - 918), Lonon, 1962.

Rayner, R.M., Aconsise history of Britain, London, 1939.

Stenton, F. M., Anglo- Saxon England, Oxford, 1947.

Trevelyan, G.M., History of England, Lonon, 1924.

Whitelock, D., The Beginning of the England Society, London, 1954.

$$
\begin{aligned}
& \text { كالكاء :ألمرا-مع العربهاء } \\
& \text { السيد الباز لعرينى (دكتور) : }
\end{aligned}
$$

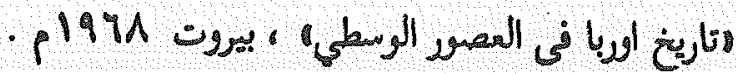

$$
\text { جوزيف نسيم يوسف (دكتور) : }
$$

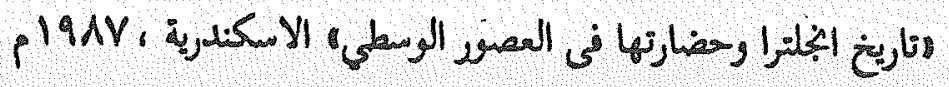

$$
\text { سميد عبد الفناح عاشور (دكتور): }
$$

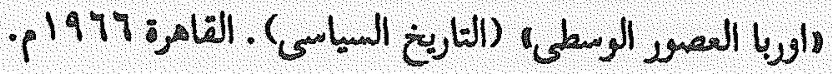

$$
\text { متحمد محمد مرنى الشيخ (دكتور): }
$$

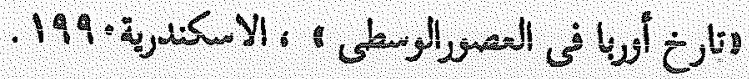

